\title{
Moral-Hazard Credit CyCles With Risk-Averse Agents
}

\author{
by Roger B. Myerson ${ }^{1}$ \\ http://home.uchicago.edu/ rmyerson/research/rabankers.pdf
}

Abstract: We consider a simple overlapping-generations model with risk-averse financial agents subject to moral hazard. Efficient contracts for such financial intermediaries involve backloaded late-career rewards. Compared to the analogous model with risk-neutral agents, risk aversion tends to reduce the growth of agents' responsibilities over their careers. This moderation of career growth rates can reduce the amplitude of the widest credit cycles, but it also can cause small deviations from steady state to amplify over time in rational-expectations equilibria. We find equilibria in which fluctuations increase until the economy enters a boom/bust cycle where no financial agents are hired in booms.

\section{Introduction and review of previous paper}

This paper shows how problems of moral hazard in financial intermediation can cause macroeconomic fluctuations in a stationary nonstochastic economic environment even when financial agents are risk averse. A previous paper (Myerson, 2012) showed how such credit cycles can be sustained over an infinite time horizon when financial agents are risk neutral. Risk neutrality is a natural simplifying assumption, but the optimal contracts for risk-neutral agents look rather extreme, with agents receiving incentive payments only at the end of their careers and then only if their investments have been successful in every period. When we assume that agents are risk averse, the analysis becomes more complicated, but the resulting optimal contracts seem more realistic, as risk-averse financial agents will get substantial rewards in every period when they supervise investments. Remarkably, we also find that the economy can become even more unstable when financial agents are risk averse.

Together with the previous paper, this paper is part of a growing theoretical literature since Bernanke and Gertler (1989) that explores how macroeconomic instability can be driven by microeconomic agency problems of moral hazard and adverse selection. References to many important papers in this literature are listed by Myerson (2012). This paper and Myerson (2012) are particularly intended to show how such instability can be driven by the simplest kinds of moral-hazard problems which might reasonably be expected to apply whenever an agent is responsible for large investments of other people's savings.

\footnotetext{
${ }^{1}$ This paper has benefited from helpful discussions with Balazs Szentes and Fernando Alvarez. Author's address: Economics Dept, University of Chicago, 1126 East 59th Street, Chicago, IL 60637 USA. Email: myerson@uchicago.edu [Current version: June 9, 2014.]
} 
Let us first review the main points from the previous paper. Since Becker and Stigler (1974) and Shapiro and Stiglitz (1984), it has been well understood in agency theory that dynamic moral-hazard problems with limited liability are efficiently solved by promising large end-of-career rewards for agents who maintain good performance records. At any point in time, a rational agent can be motivated to exert hidden efforts by the possibility of future rewards but not by earlier rewards that have already been received. Thus, an end-of-career reward can be most effective, because it can motivate efforts at every period of an agent's career.

But standard assumptions about the discounting of future rewards imply that the motivating value of any specific end-of-career reward will become greater as the agent gets closer to the end of her career. Thus, under efficient moral-hazard incentive contracts, agents' responsibilities should be expected to grow over time during their careers. Myerson (2012) showed that, when such efficient agency contracts are imbedded in a general dynamic model of the whole economy, this expected career growth of financial agents' responsibilities can cause general equilibria to be dynamically unstable.

The back-loading of moral-hazard agency rents requires that financial agents must anticipate some kind of long-term relationship with investors. The aggregate value of these relationships for mid-career financial agents at any point in time may be considered as a state of the dynamic economy, and this state can change over time. When trusted mid-career financial agents are relatively scarce, investment is reduced, and the result is a recession. A larger cohort of new young agents may be then recruited to help fill the gap. But competitive recruitment of new agents cannot fully remedy such an undersupply of financial intermediation, because the moral-hazard incentive constraints imply that agents can be hired efficiently only as part of a long-term career plan in which their expected responsibilities tend to grow during their careers. Because of this expected growth of agents' responsibilities, a large adjustment to reach steadystate financial capacity in one period would create excess financial capacity in the future. Thus, in the model of Myerson (2012), the recovery from a recession must move gradually up into a boom, when the economy will have an excess of financial intermediaries relative to what can be sustained in the steady state. This boom, in turn, will contain the seeds of a future recession that will occur after the large cohort of financial agents retires.

In the model with risk-neutral agents of Myerson (2012), a financial agent can manage one investment of any size in each of $\mathrm{n}$ periods in her career, after which the agent may retire to 
enjoy end-of-career rewards in her last $(n+1$ 'th) period of life. An ample supply of new young agents is assumed to be available in every period, but they will be only hired under efficient $n$ period incentive contracts. Expected profit rates for investments in each period will depend on aggregate investment in that period according to a given investment-demand function, which is stationary and nonstochastic. Aggregate investment is determined by the availability of trusted financial agents who must supervise it, including both young agents who get new n-period contracts this period and older mid-career agents who are working under previously agreed contracts. Investment funds are elastically supplied and so, in equilibrium, investors can only earn normal returns after paying agents' rewards. This equilibrium condition implies that expected profit rates over any interval of $n$ periods must sum to a constant that is just what it takes to cover the agents' expected moral-hazard rents over an n-period career. The dynamic equilibria of Myerson (2012) are characterized by cycles that repeat every $\mathrm{n}$ periods. There is a steady-state equilibrium that applies for one vector of initial conditions, but the economy has no tendency toward (or away from) steady state from any other initial conditions.

In this paper, we drop the risk-neutrality assumption of the previous paper, and instead we consider risk-averse agents whose utility in any period is their current consumption raised to some exponent $\theta$ that is less than 1 . Nonlinear utility is much harder to analyze, and so the analysis is simplified here by considering only the simple overlapping-generations case of $n=2$. That is, each financial agent can manage investments in two periods, first as a young agent, then as an old agent, after which the agent has one period of retirement. So in this model, the dynamic state of the economy in any period is the aggregate value of the mid-career investmentmanagement positions that have been promised to old agents under contracts that were signed in the preceding period, when they were young.

At the micro-agency level, the effect of risk aversion in this model is to reduce the expected rate of growth of agents' responsibilities during their careers, because optimal contracts will include significant incentive payments in each period of an agent's career, not only at the end. As this expected growth of responsibilities is what makes the model dynamically unstable, one might conjecture that economic instability would be reduced as the expected career growth rate is reduced. In one sense this conjecture might be true, as we can find examples (see Figures 2 and 6) where the amplitude of equilibrium cycles with risk aversion is less than the amplitude of the widest possible cycle with risk neutrality (with all other parameters the same). But in 
another important sense this conjecture is false, because we find here that small deviations from the steady state tend to grow larger over time in the model with risk aversion. That is, the steady state is not locally stable in our model with risk-averse agents. Such amplification of small deviations from steady state does not occur in the risk-neutral model of Myerson (2012), where initial conditions that are close to steady state yield cycles that stay close to steady state.

This new form of instability of equilibria with risk aversion occurs because, in the calculations of investors who might hire a young agent with a two-period contract, a lower expected growth of the risk-averse agent's investment responsibilities tends to reduce the weight on the profit rate for investments in the agent's second period. So the equilibrium condition of zero expected net profits for competitive investors implies that, in any period when new young agents are hired, any deviation of profit rates from the steady-state level in this period must be balanced by a larger deviation of profit rates in the next period. Thus, in a dynamic equilibrium with rational expectations, deviations from steady-state profit rates must grow until the economy reaches a maximal cycle in which new young agents are only hired every other period. That is, for a wide range of parameters, inequality of opportunities across periods has a natural tendency to increase in the dynamic equilibria of our economy.

The plan of this paper is as follows. The formal model of a dynamic economy with riskaverse financial agents is defined in Section 2. Equilibria of the model are characterized in Section 3. In particular, we find in Section 3 a broad parametric class of examples where the steady state is locally unstable and the dynamic economy tends toward an extreme cycle of peaks and troughs, in which new agents are hired only after the economy has fallen into a recession. In Section 4, we examine efficiency properties of these dynamic equilibria, and we consider some policies that a government could use to reduce generational inequalities and stabilize the economy. Section 5 shows how some results may extend to economies where risk-averse agents serve more than two periods. Section 6 analyzes a related model in which financial agents are risk neutral but have different discount rates from investors. This related model offers a useful perspective on our main model with risk-averse agents because, like risk aversion, making agents more patient also reduces their expected career growth of responsibilities. (So readers may want to look at Section 6 before other sections.) Conclusions are summarized in Section 7.

Appendix A provides details on how optimal contracts can be computed for our model with risk-averse agents. Appendix B presents a method for computing dynamic equilibria in the 
regular case where the steady state is locally unstable.

\section{The model}

We consider a simple dynamic economy in discrete time, with one commodity which in any period can be either consumed or invested in a project that will yield returns in the next period. This economy is on an island in a world where funds for investment are freely mobile. But all investment in this island economy must be managed by local agents who live on the island and who are subject to moral-hazard temptations to mismanage investments. Each agent lives three periods and can manage one project in each of her first two periods. In her third period, the agent must retire, as she cannot take responsibility for a project that will yield its returns after the end of her life.

We assume here that an agent's utility in any period is some exponential power $\theta$ of the agent's current consumption, where this utility parameter $\theta$ satisfies $\theta<1$, with $\theta \neq 0$. (The case of logarithmic utility is not explicitly considered here but can be subsumed by limits as $\theta \rightarrow 0$.) Agents discount their future utility by the per-period discount factor $\delta$, where $0<\delta<1$. Let us consider an agent who will work in periods $t$ and $t+1$ and then retire in period $t+2$. Such an agent wants to maximize the expected total discounted value of her lifetime utility

$$
\left(\mathrm{c}_{0}{ }^{\theta}+\delta \mathrm{c}_{1}{ }^{\theta}+\delta^{2} \mathrm{c}_{2}{ }^{\theta}\right) / \theta
$$

where each $c_{s}>0$ denotes the agent's consumption in period $t+s$. (Dividing by $\theta$ here guarantees that utility is increasing in consumption even when $\theta$ is negative, as $d / \mathrm{dc}_{\mathrm{s}}\left(\mathrm{c}_{\mathrm{s}}{ }^{\theta} / \theta\right)=\mathrm{c}_{\mathrm{s}}{ }^{\theta-1}>0$.) With $\theta<1$, this $\theta$ power of consumption is a concave utility function with constant relative risk aversion, and so we can refer to these agents as risk averse. Even though they face no actual risk in this model, their decreasing marginal utility of consumption in each period is significant here.

Investment projects on the island come in a wide range of sizes, where the size of an investment project at time $\mathrm{t}$ is the amount invested in it at time $\mathrm{t}$. Regardless of size, an agent can manage only one project in any period. The agent always has a hidden choice to either manage her project well or to mismanage it. Mismanagement of a project diverts a $\gamma$ fraction of the invested amount into the agent's personal funds available for current and future consumption, where $0<\gamma<1$. The mismanagement of an investment at any period $t$ would become evident in the next period $t+1$, but by then the agent could have fled with any personal funds to live and 
consume in some safe haven abroad for the rest of her life. Savings from these funds could be invested at the market interest rate, which is assumed to be $1 / \delta-1$ per period.

Thus, under an incentive plan that would pay an agent enough to consume $c_{s}$ in period $t+s$ when the agent manages an investment project of size $h_{s} \geq 0$, mismanagement of this project would increase the agent's current available funds to $c_{s}+\gamma h_{s}$, but these funds would then have to cover all the agents' consumption for the rest of her life abroad. For mismanagement in the agent's first period when $s=0$, the optimal constant consumption that the agent could achieve with the funds $\mathrm{c}_{0}+\gamma \mathrm{h}_{0}$ over three periods at the $\delta$ discount factor would be $\left(\mathrm{c}_{0}+\gamma \mathrm{h}_{0}\right) /\left(1+\delta+\delta^{2}\right)$, which over the next three periods would yield utility

$$
\left(1+\delta+\delta^{2}\right)\left[\left(\mathrm{c}_{0}+\gamma \mathrm{h}_{0}\right) /\left(1+\delta+\delta^{2}\right)\right]^{\theta} / \theta=\left(1+\delta+\delta^{2}\right)^{1-\theta}\left(\mathrm{c}_{0}+\gamma \mathrm{h}_{0}\right)^{\theta} / \theta .
$$

For mismanagement in the agent's second period when $s=1$, the optimal constant consumption that the agent could achieve with the funds $\mathrm{c}_{1}+\gamma \mathrm{h}_{1}$ over two periods at the $\delta$ discount factor would be $\left(c_{1}+\gamma h_{1}\right) /(1+\delta)$, which over the next two periods would yield utility

$$
(1+\delta)\left[\left(\mathrm{c}_{1}+\gamma \mathrm{h}_{1}\right) /(1+\delta)\right]^{\theta} / \theta=(1+\delta)^{1-\theta}\left(\mathrm{c}_{1}+\gamma \mathrm{h}_{1}\right)^{\theta} / \theta .
$$

For an investment $h$ in any period $t$, the returns in period $t+1$ will be $\left(1+p_{t}\right) h / \delta$ if the agent manages the investment well, but the returns will be 0 if it fails. Thus, the expected $\mathrm{t}$-discounted return from a well-managed investment $\mathrm{h}$ at period $\mathrm{t}$ is $\left(1+\mathrm{p}_{\mathrm{t}}\right) \mathrm{h}$. With $\mathrm{p}_{\mathrm{t}} \geq 0$ and $\gamma<1$, mismanaged investment projects will never be worthwhile.

We assume that this economy is an island in a larger world where the global supply of investment funds is perfectly elastic at the discount factor $\delta$ as long as global investors can get nonnegative expected net discounted profits, after paying the agents in a way that will motivate them to manage investments appropriately. We may let $I_{t}$ denote the total aggregate investment in this economy in any period t. Increasing production costs or shifting terms of trade may tend to decrease the expected returns from investments in periods when total aggregate investment is greater. So we assume that, in any period $t$, the expected profit rate $\mathrm{p}_{\mathrm{t}}$ is related to current aggregate investment $\mathrm{I}_{\mathrm{t}}$ by a given decreasing investment-demand function

$$
\mathrm{I}_{\mathrm{t}}=\mathrm{I}\left(\mathrm{p}_{\mathrm{t}}\right) \geq 0 \text {. }
$$

We assume that, at every period $t$, there is a large and ample supply of new young agents who are qualified and eager to start managing large investments of other people's funds. Thus, at any time $\mathrm{t}$, investors can hire young agents to manage investments over the next two periods, 
with two-period contracts that are designed optimally for investors, subject to the constraints that the agent must have an appropriate incentive to manage any investment well. In hiring a young agent at time $\mathrm{t}$, the investors' contracting problem may be written as follows:

$$
\begin{array}{lr}
\begin{array}{lr}
\operatorname{maximize} \mathrm{h}_{0} \mathrm{p}_{\mathrm{t}}+\delta \mathrm{h}_{1} \mathrm{p}_{\mathrm{t}+1}-\mathrm{c}_{0}-\delta \mathrm{c}_{1}-\delta^{2} \mathrm{c}_{2} & \\
\text { subject to }\left(\mathrm{h}_{0}, \mathrm{c}_{0}, \mathrm{~h}_{1}, \mathrm{c}_{1}, \mathrm{c}_{2}\right) \geq 0, \mathrm{~h}_{0}=1, & \text { (nonnegativity, normalization) } \\
\left(\mathrm{c}_{1}{ }^{\theta}+\delta \mathrm{c}_{2}{ }^{\theta}\right) / \theta \geq(1+\delta)\left[\left(\mathrm{c}_{1}+\gamma \mathrm{h}_{1}\right) /(1+\delta)\right]^{\theta} / \theta & (\text { moral hazard at } t+1) \\
\left(\mathrm{c}_{0}{ }^{\theta}+\delta \mathrm{c}_{1}{ }^{\theta}+\delta^{2} \mathrm{c}_{2}{ }^{\theta}\right) / \theta \geq\left(1+\delta+\delta^{2}\right)\left[\left(\mathrm{c}_{0}+\gamma \mathrm{h}_{0}\right) /\left(1+\delta+\delta^{2}\right)\right]^{\theta} / \theta & (\text { moral hazard at } t)
\end{array}
\end{array}
$$

Here in each period $t+s, h_{s}$ is the size of the investment project that the agent is to manage and $c_{s}$ is the amount paid to the agent for current consumption under the planned contract. With the expected profit rates $\mathrm{p}_{\mathrm{t}}$ and $\mathrm{p}_{\mathrm{t}+1}$ for the agent's first and second investments, after subtracting the cost of incentive pay for the agent, the investors' expected discounted net profit is as shown in the objective function to be maximized in this optimization problem. This objective is linear because we assume that investors are risk neutral with respect to the returns from this contract, as each investor's share in it may be a small part of a well-diversified portfolio.

We can normalize the initial investment $h_{0}$ to equal 1 here, because the contracting problem [1] is otherwise homogeneous in the contract $\left(\mathrm{h}_{0}, \mathrm{c}_{0}, \mathrm{~h}_{1}, \mathrm{c}_{1}, \mathrm{c}_{2}\right)$. Notice that, with this normalization, the optimal contracts in this problem do not depend on $\mathrm{p}_{\mathrm{t}}$.

If investors could earn positive expected profits from a feasible contract this period, they would want to hire more young agents and increase investments, thus driving profit rates down until investments with new young agents earn zero expected profits over their careers. So let $\mathrm{Y}\left(\mathrm{p}_{\mathrm{t}+1}\right)$ be the first-period profit rate $\mathrm{p}_{\mathrm{t}}$ at which investors could just expect to break even in hiring a young agent with an optimal contract when the expected profit rate for second-period investments will be $\mathrm{p}_{\mathrm{t}+1}$. Thus, we have

$$
\mathrm{Y}\left(\mathrm{p}_{\mathrm{t}+1}\right)=\mathrm{c}_{0}+\delta \mathrm{c}_{1}+\delta^{2} \mathrm{c}_{2}-\delta \mathrm{h}_{1} \mathrm{p}_{\mathrm{t}+1}
$$

for any $\left(\mathrm{c}_{0}, \mathrm{~h}_{1}, \mathrm{c}_{1}, \mathrm{c}_{2}\right)$ that form an optimal contract in problem [1] with the normalization $\mathrm{h}_{0}=1$. This $\mathrm{Y}$ is a decreasing function.

Let $\mathrm{G}\left(\mathrm{p}_{\mathrm{t}+1}\right)=\mathrm{h}_{1} / \mathrm{h}_{0}$ for an optimal solution of the contracting problem [1]. That is, $\mathrm{G}\left(\mathrm{p}_{\mathrm{t}+1}\right)$ is the expected growth in agents' responsibilities from young at time to old at time $\mathrm{t}+1$, when $p_{t+1}$ is the anticipated profit rate for investments period $t+1$. This $G$ is an increasing nonnegative-valued function. By the envelope theorem, 


$$
\mathrm{Y}^{\prime}\left(\mathrm{p}_{\mathrm{t}+1}\right)=-\delta \mathrm{G}\left(\mathrm{p}_{\mathrm{t}+1}\right) .
$$

Because utility is a nonlinear function of consumption, it may be more convenient to measure an agents' welfare in terms of the constant-equivalent consumption that would yield the same expected utility if consumed now and in every future period of the agent's life. Given any optimal solution to the contracting problem [1] above, we may let $\mathrm{v}_{1}$ denote the constant equivalent consumption for the old agent beginning in period $t+1$. That is, $\mathrm{v}_{1}$ satisfies

$$
(1+\delta) \mathrm{v}_{1}{ }^{\theta} / \theta=\left(\mathrm{c}_{1}{ }^{\theta}+\delta \mathrm{c}_{2}{ }^{\theta}\right) / \theta \text { and so } \mathrm{v}_{1}=\left[\left(\mathrm{c}_{1}{ }^{\theta}+\delta \mathrm{c}_{2}{ }^{\theta}\right) /(1+\delta)\right]^{1 / \theta} \text {. }
$$

The formula makes $\mathrm{v}_{1}$ linearly homogeneous in $\mathrm{c}_{1}$ and $\mathrm{c}_{2}$. If we renormalized the optimal contracting problem to some other value of $\mathrm{h}_{0}$, the old agent's constant-equivalent consumption $\mathrm{v}_{1}$ would linearly co-vary with the contract variables $\left(\mathrm{h}_{0}, \mathrm{c}_{0}, \mathrm{~h}_{1}, \mathrm{c}_{1}, \mathrm{c}_{2}\right)$.

So let $\mathrm{H}\left(\mathrm{p}_{\mathrm{t}+1}\right)=\mathrm{h}_{1} / \mathrm{v}_{1}$ for an optimal solution $\left(\mathrm{h}_{0}, \mathrm{c}_{0}, \mathrm{~h}_{1}, \mathrm{c}_{1}, \mathrm{c}_{2}\right)$ to the contracting problem [1]. That is, when the profit rate on investments at time $t+1$ is $p_{t+1}, H\left(p_{t+1}\right)$ will be the old agents' investment responsibilities at time $t+1$ per unit of constant-equivalent consumption that has been contractually promised to them (for appropriately managing investments in the previous period when they were young). This $\mathrm{H}$ is an increasing nonnegative-valued function.

In the case of $p_{t+1}=0$, we may get a strictly positive value of $h_{1}$ in some optimal solutions to problem [1], but then there would be alternative optima with smaller $h_{1}$, as the investors would lose nothing by reducing their profitless investments in period $t+1$. In that case, we could reinterpret $\mathrm{G}$ and $\mathrm{H}$ at 0 as multi-valued functions or correspondences, each of which can take at 0 any value in some interval which always includes $\mathrm{G}(0)=0$ and $\mathrm{H}(0)=0$.

We are assuming that investors can hire young agents in any period t, under optimal contracts to manage investments in periods $t$ and $t+1$ when investments have the expected profit rates $\mathrm{p}_{\mathrm{t}}$ and $\mathrm{p}_{\mathrm{t}+1}$. Let $\mathrm{J}_{\mathrm{t}}$ denote the total investments in the economy that are managed by young agents in period $t$. If profits $\mathrm{p}_{\mathrm{t}}$ in period $\mathrm{t}$ were greater than $\mathrm{Y}\left(\mathrm{p}_{\mathrm{t}+1}\right)$, then investors could expect positive surplus by hiring young agents to invest more, thus decreasing $\mathrm{p}_{\mathrm{t}}$. So in equilibrium, in any period $t$, we must have $\mathrm{p}_{\mathrm{t}} \leq \mathrm{Y}\left(\mathrm{p}_{\mathrm{t}+1}\right)$, and if $\mathrm{J}_{\mathrm{t}}>0$ then we must have $\mathrm{p}_{\mathrm{t}}=\mathrm{Y}\left(\mathrm{p}_{\mathrm{t}+1}\right)$. Then, under optimal contracts, the aggregate investment responsibilities of young agents from period $t$ should grow to $\mathrm{J}_{\mathrm{t}} \mathrm{G}\left(\mathrm{p}_{\mathrm{t}+1}\right)$ in period $\mathrm{t}+1$ when they are old agents.

Initial contracts may promise some total constant-equivalent consumption $\mathrm{V}_{0}$ to old agents in period 1. Given this initial condition, an equilibrium is a sequence of profit rates $\mathrm{p}_{\mathrm{t}}$ and young investment responsibilities $\mathrm{J}_{\mathrm{t}}$ for each period $\mathrm{t} \in\{1,2,3, \ldots\}$ that satisfy 


$$
\begin{aligned}
& \mathrm{I}\left(\mathrm{p}_{1}\right)=\mathrm{V}_{0} \mathrm{H}\left(\mathrm{p}_{1}\right)+\mathrm{J}_{1}, \quad \mathrm{I}\left(\mathrm{p}_{\mathrm{t}+1}\right)=\mathrm{J}_{\mathrm{t}} \mathrm{G}\left(\mathrm{p}_{\mathrm{t}+1}\right)+\mathrm{J}_{\mathrm{t}+1}, \\
& \mathrm{~J}_{\mathrm{t}} \geq 0, \quad 0 \leq \mathrm{p}_{\mathrm{t}} \leq \mathrm{Y}\left(\mathrm{p}_{\mathrm{t}+1}\right), \text { and }\left[\mathrm{p}_{\mathrm{t}}-\mathrm{Y}\left(\mathrm{p}_{\mathrm{t}+1}\right)\right] \mathrm{J}_{\mathrm{t}}=0, \forall \mathrm{t} \in\{1,2,3, \ldots\}
\end{aligned}
$$

\section{Analysis of dynamic equilibria}

The function $\mathrm{Y}\left(\mathrm{p}_{\mathrm{t}+1}\right)$, which determines equilibrium profit rates in period $\mathrm{t}$ for young agents to be hired then, is a decreasing continuous function of the next-period profit rate $\mathrm{p}_{\mathrm{t}+1}$, and $\mathrm{Y}(0)>0$. So between 0 and $\mathrm{Y}(0)$, there exists a steady-state profit rate $\mathrm{p}^{*}$ such that

$$
\mathrm{p}^{*}=\mathrm{Y}\left(\mathrm{p}^{*}\right) \text {. }
$$

To keep things interesting, let us assume that investment is positive in the steady state, that is $\mathrm{I}\left(\mathrm{p}^{*}\right)>0$. Then in a steady-state equilibrium, investors would hire new young agents each period to manage aggregate investments $\mathrm{J}^{*}$ such that

$$
\mathrm{J}^{*}=\mathrm{I}\left(\mathrm{p}^{*}\right) /\left(1+\mathrm{G}\left(\mathrm{p}^{*}\right)\right),
$$

while old agents would manage $\mathrm{G}\left(\mathrm{p}^{*}\right) \mathrm{J}^{*}$. This steady-state equilibrium can apply when the initial condition is $\mathrm{V}_{0}=\mathrm{V}^{*}=\mathrm{G}\left(\mathrm{p}^{*}\right) \mathrm{J}^{*} / \mathrm{H}\left(\mathrm{p}^{*}\right)$.

The dynamics of equilibria from other initial conditions near the steady state depend critically on the expected growth ratio $\mathrm{G}\left(\mathrm{p}^{*}\right)$. There are three broad cases to consider: when $\mathrm{G}\left(\mathrm{p}^{*}\right)$ is less than 1 , when $\mathrm{G}\left(\mathrm{p}^{*}\right)$ is between 1 and $1 / \delta$, and when $\mathrm{G}\left(\mathrm{p}^{*}\right)$ is greater than $1 / \delta$. Figure 1 shows where these three cases occur for different values of the risk-aversion parameter $\theta$ and the discount factor $\delta$. (G(p*) does not actually depend on the moral-hazard parameter $\gamma$.) The case of $\mathrm{G}\left(\mathrm{p}^{*}\right) \leq 1$ is found in the region above the solid line in Figure 1, where $\delta$ is relatively high and $\theta$ is low. The case of $\mathrm{G}\left(\mathrm{p}^{*}\right) \geq 1 / \delta$ is found only in the strip on the right between the dotted lines in Figure 1, where $\theta$ is never less than 0.5 . For all other parametric values, in a wide region including all cases of sufficiently low $\delta$ for $\theta \leq 0.5$, we get the intermediate case of 1 $<\mathrm{G}\left(\mathrm{p}^{*}\right)<1 / \delta$, which yields particularly interesting equilibrium dynamics.

\section{[Insert Figure 1 about here]}

The simplest case to consider first is when $\mathrm{G}\left(\mathrm{p}^{*}\right) \leq 1$ so that, in a steady state, agents' responsibilities would not be expected to increase in their second period. In this case, an equilibrium from any initial condition $\mathrm{V}_{0}$ always has $\mathrm{p}_{\mathrm{t}+1}=\mathrm{p}^{*}$ for all $\mathrm{t} \geq 1$. In such an equilibrium, we must have

$$
\mathrm{J}_{\mathrm{t}+1}+\mathrm{G}\left(\mathrm{p}^{*}\right) \mathrm{J}_{\mathrm{t}}=\mathrm{I}\left(\mathrm{p}^{*}\right)=\left(1+\mathrm{G}\left(\mathrm{p}^{*}\right)\right) \mathrm{J}^{*}, \text { and so } \mathrm{J}_{\mathrm{t}+1}-\mathrm{J}^{*}=-\mathrm{G}\left(\mathrm{p}^{*}\right)\left(\mathrm{J}_{\mathrm{t}}-\mathrm{J}^{*}\right)
$$


for all $t \geq 1$. We can construct such a bounded sequence, with all $J_{t} \geq 0$ when $G\left(p^{*}\right) \leq 1$. (If $\mathrm{V}_{0} \leq \mathrm{I}\left(\mathrm{p}^{*}\right) / \mathrm{H}\left(\mathrm{p}^{*}\right)$ then we start at $\mathrm{p}_{1}=\mathrm{p}^{*}$ with $\mathrm{J}_{1}=\mathrm{I}\left(\mathrm{p}^{*}\right)-\mathrm{V}_{0} \mathrm{H}\left(\mathrm{p}^{*}\right)$. Otherwise, if $\mathrm{V}_{0}>\left(\mathrm{p}^{*}\right) / \mathrm{H}\left(\mathrm{p}^{*}\right)$, we may start with $\mathrm{J}_{1}=0$ at some $\mathrm{p}_{1}<\mathrm{p}^{*}$ satisfying $\mathrm{V}_{0}=\mathrm{I}\left(\mathrm{p}_{1}\right) / \mathrm{H}\left(\mathrm{p}_{1}\right)$.) Thus, the steady state is a stable equilibrium when $\mathrm{G}\left(\mathrm{p}^{*}\right) \leq 1$.

In the rest of this paper we will focus generally on the cases where $G\left(p^{*}\right)>1$, so that we get equilibria with nontrivial dynamics. It is useful to consider first what the dynamics would look like in a neighborhood of the steady state $\mathrm{p}^{*}$, where

$$
\mathrm{Y}(\mathrm{p}) \approx \mathrm{Y}\left(\mathrm{p}^{*}\right)+\mathrm{Y}^{\prime}\left(\mathrm{p}^{*}\right)\left(\mathrm{p}-\mathrm{p}^{*}\right)=\mathrm{p}^{*}-\delta \mathrm{G}\left(\mathrm{p}^{*}\right)\left(\mathrm{p}-\mathrm{p}^{*}\right) .
$$

So when profit rates are near $\mathrm{p}^{*}$ and investors are willing to hire new agents each period $\left(\mathrm{J}_{\mathrm{t}}>0\right)$, the update equation $\mathrm{p}_{\mathrm{t}}=\mathrm{Y}\left(\mathrm{p}_{\mathrm{t}+1}\right)$ implies

$$
\mathrm{p}_{\mathrm{t}}-\mathrm{p}^{*}=\mathrm{Y}\left(\mathrm{p}_{\mathrm{t}+1}\right)-\mathrm{p}^{*} \approx-\delta \mathrm{G}\left(\mathrm{p}^{*}\right)\left(\mathrm{p}_{\mathrm{t}+1}-\mathrm{p}^{*}\right) .
$$

The negative coefficient here tells us that the profit rates must cycle around the steady state, going above and below it in alternating periods. In the case where $\mathrm{G}\left(\mathrm{p}^{*}\right)>1 / \delta$, this approximate equality implies that $\left|\mathrm{p}_{\mathrm{t}}-\mathrm{p}^{*}\right|>\left|\mathrm{p}_{\mathrm{t}+1}-\mathrm{p}^{*}\right|$, and so dynamic equilibria near the steady state will tend to converge toward the steady state. But in the case where $1<\mathrm{G}\left(\mathrm{p}^{*}\right)<1 / \delta$, this approximate equality tells us that $\left|\mathrm{p}_{\mathrm{t}}-\mathrm{p}^{*}\right|<\left|\mathrm{p}_{\mathrm{t}+1}-\mathrm{p}^{*}\right|$, and so equilibrium credit cycles that start near steady state $\mathrm{p}^{*}$ must tend to increase in amplitude, moving away from $\mathrm{p}^{*}$.

In the corresponding model with risk-neutral agents, the expected growth ratio of agent's responsibilities from one period to the next $(\mathrm{G}(\mathrm{p}))$ is always equal to $1 / \delta$, the reciprocal of the agents' discount factor (see Myerson, 2012, and Section 6 here). But when agents are risk averse, we can get examples where $\mathrm{G}\left(\mathrm{p}^{*}\right)$ can be greater or less than $1 / \delta$. It may be particularly interesting to look at an example where $1<\mathrm{G}\left(\mathrm{p}^{*}\right)<1 / \delta$.

To illustrate this case, let us consider a baseline example with parameters ${ }^{2}$

$$
\theta=0.5, \delta=0.5, \gamma=0.25, \mathrm{I}(\mathrm{p})=1.5 \max \{1-\mathrm{p} / 0.7,0\} .
$$

(In a model where an agent's career spans two periods, each period could be interpreted as 20 years, so that a per-period discount factor of $\delta=0.5$ would correspond to an annual discount factor of $(0.5)^{1 / 20}=0.966$, or an annual discount rate of $3.4 \%$, which seems quite reasonable.) Optimal contracts and dynamic equilibria for this example can be computed with formulas from the Appendix. The steady-state profit rate for this example is $\mathrm{p}^{*}=0.231$. In the optimal

\footnotetext{
${ }^{2}$ All calculations are available in a spreadsheet at http://home.uchicago.edu/ rmyerson/research/rabankers.xls .
} 
contract for a young agent managing one unit of investment $h_{0}=1$ with next-period's profit rate being $\mathrm{p}^{*}$, the agent's first period consumption is $\mathrm{c}_{0}=0.038$ (much less than the $\gamma \mathrm{h}_{0}=0.25$ that the agent could take by mismanaging). If the agent's first-period investment is well managed, then the old agent next period will consume $c_{1}=0.275$, will get to manage $h_{1}=1.727$, and will be promised retirement consumption $\mathrm{c}_{2}=1.021$ after managing another investment well. (The prospect of consuming this $c_{1}$ and $c_{2}$ yield the same utility for the old agent as the constantequivalent consumption $\mathrm{v}_{1}=0.472$ in both periods.) With the given investment demand curve, aggregate investment in steady state is $\mathrm{I}\left(\mathrm{p}^{*}\right)=1.004$, of which total amount managed by young agents each period is $\mathrm{J}^{*}=0.368$. The initial aggregate value of the constant-equivalent consumption promises to old agents that would lead to the steady-state equilibrium is $\mathrm{V}^{*}=0.174$.

Table 1 shows optimal contracts for the steady-state profit rate $\mathrm{p}^{*}$ are shown for other values of the utility exponent $\theta$, holding fixed $\delta=0.5$ and $\gamma=0.25$. With these parameters, the case of $1<\mathrm{G}\left(\mathrm{p}^{*}\right)<1 / \delta$ is satisfied for all $\theta$ between -1.47 and 0.73 , which includes our above example [4] where $\theta=0.5$.

\section{[Insert Table 1 about here]}

The growth ratio at steady state is for this example [4] is $\mathrm{G}\left(\mathrm{p}^{*}\right)=\mathrm{h}_{1}=1.727$, and so this example indeed satisfies $1<\mathrm{G}\left(\mathrm{p}^{*}\right)<1 / \delta=2$. Thus, its dynamic equilibria must cycle away from the steady state, even when the initial conditions are very close to the steady state. An example of such a dynamic equilibrium is shown in Figures 2, 3 and 4. Here the initial condition at period 1 is $\mathrm{V}_{0}=0.180$, which is about $3 \%$ above the steady-state $\mathrm{V}^{*}=0.174$, and the initial $\mathrm{p}_{1}$ $=0.229$ is less than $1 \%$ below the steady-state $\mathrm{p}^{*}$. But the cyclical deviations from steady state grow until the equilibrium enters an absorbing cycle after period $\mathrm{T}=25$. Let us now consider the nature of this absorbing cycle.

\section{[Insert Figures 2, 3, and 4 about here]}

The update equation $\mathrm{p}_{\mathrm{t}}=\mathrm{Y}\left(\mathrm{p}_{\mathrm{t}+1}\right)$, which we have used to characterize the evolution of profit rates (and which is approximated by condition [3] near the steady state), applies only in periods where investors are willing to hire new young agents in this economy. So when the update equation yields unstable dynamics, the amplification of deviations from steady state can end when the economy enters an extreme cycle in which either there are regularly-occurring 
periods in which investors do not hire any new young agents, or the update equation itself must become stable. In fact, the first of these possibilities has been found in all known examples, and so it may be called the regular case. But this author has not been able to rule out the second alternative possibility. The following fact summarizes this result.

Fact 1. Suppose that $1<\mathrm{G}\left(\mathrm{p}^{*}\right)<1 / \delta$. Then either (in the regular case) there exists an extreme cycle $\left(\mathrm{q}_{1} . \mathrm{q}_{2}\right)$ such that

$$
\begin{aligned}
& \mathrm{q}_{0}=\mathrm{Y}\left(\mathrm{q}_{1}\right), \mathrm{G}\left(\mathrm{q}_{1}\right)=\mathrm{I}\left(\mathrm{q}_{1}\right) / \mathrm{I}\left(\mathrm{q}_{0}\right), \mathrm{q}_{1}<\mathrm{p}^{*}<\mathrm{q}_{0}, \\
& \text { and } \mathrm{p}<\mathrm{Y}(\mathrm{Y}(\mathrm{p})) \text { for all } \mathrm{p} \text { such that } \mathrm{q}_{1} \leq \mathrm{p}<\mathrm{p}^{*} ;
\end{aligned}
$$

or else (the alternative case) there exists a cycle $\left(\mathrm{r}_{0}, \mathrm{r}_{1}\right)$ with $\hat{\mathrm{J}}_{0} \geq 0$ and $\hat{\mathrm{J}}_{1} \geq 0$ such that

$$
\mathrm{r}_{0}=\mathrm{Y}\left(\mathrm{r}_{1}\right), \mathrm{r}_{1}=\mathrm{Y}\left(\mathrm{r}_{0}\right), \hat{\mathrm{J}}_{0}+\mathrm{G}\left(\mathrm{r}_{0}\right) \hat{\mathrm{J}}_{1}=\mathrm{I}\left(\mathrm{r}_{0}\right), \hat{\mathrm{J}}_{1}+\mathrm{G}\left(\mathrm{r}_{1}\right) \hat{\mathrm{J}}_{0}=\mathrm{I}\left(\mathrm{r}_{1}\right) \text {. }
$$

Proof. With $\mathrm{G}\left(\mathrm{p}^{*}\right)>1$, we have $\mathrm{G}\left(\mathrm{p}^{*}\right)>\mathrm{I}\left(\mathrm{p}^{*}\right) / \mathrm{I}\left(\mathrm{Y}\left(\mathrm{p}^{*}\right)\right)=1$. But with $\mathrm{G}(0)=0 \leq$ $\mathrm{I}(0) / \mathrm{I}(\mathrm{Y}(0))$, there must exist some $\mathrm{q}_{1}$ such that $0 \leq \mathrm{q}_{1}<\mathrm{p}^{*}$ such that $\mathrm{G}\left(\mathrm{q}_{1}\right)=\mathrm{I}\left(\mathrm{q}_{1}\right) / \mathrm{I}\left(\mathrm{Y}\left(\mathrm{q}_{1}\right)\right)$. With $\mathrm{G}\left(\mathrm{p}^{*}\right)<1 / \delta$, we have $\left|\mathrm{Y}^{\prime}\left(\mathrm{p}^{*}\right)\right|=\delta \mathrm{G}\left(\mathrm{p}^{*}\right)<1$, and so the derivative $\mathrm{d} / \mathrm{dp} \mathrm{Y}(\mathrm{Y}(\mathrm{p}))=$ $\mathrm{Y}^{\prime}(\mathrm{Y}(\mathrm{p})) \mathrm{Y}^{\prime}(\mathrm{p})$ at $\mathrm{p}^{*}$ is $\left(\mathrm{Y}^{\prime}\left(\mathrm{p}^{*}\right)\right)^{2}<1$. So we have $\mathrm{p}<\mathrm{Y}(\mathrm{Y}(\mathrm{p}))$ for all $\mathrm{p}<\mathrm{p}^{*}$ in some neighborhood of $\mathrm{p}^{*}$. If this neighborhood includes $\mathrm{q}_{1}$ then the regular case is satisfied with $\mathrm{q}_{0}=\mathrm{Y}\left(\mathrm{q}_{1}\right)$. If not, the lower bound of the neighborhood would be some $\mathrm{r}_{1}<\mathrm{p}^{*}$ such that

$$
\mathrm{r}_{1}=\mathrm{Y}\left(\mathrm{Y}\left(\mathrm{r}_{1}\right)\right) \text { and } \mathrm{G}\left(\mathrm{r}_{1}\right)>\mathrm{I}\left(\mathrm{r}_{1}\right) / \mathrm{I}\left(\mathrm{Y}\left(\mathrm{r}_{1}\right)\right)>1 \text {. }
$$

But then $r_{0}=Y\left(r_{1}\right)>p^{*}$ would also satisfy

$$
\mathrm{G}\left(\mathrm{r}_{0}\right)>\mathrm{G}\left(\mathrm{p}^{*}\right)>1>\mathrm{I}\left(\mathrm{r}_{0}\right) / \mathrm{I}\left(\mathrm{r}_{1}\right)=\mathrm{I}\left(\mathrm{r}_{0}\right) / \mathrm{I}\left(\mathrm{Y}\left(\mathrm{r}_{0}\right)\right),
$$

and so the alternative case could be satisfied with $\hat{J}_{1}=\left[G\left(r_{1}\right) I\left(r_{0}\right)-I\left(r_{1}\right)\right] /\left[G\left(r_{1}\right) G\left(r_{0}\right)-1\right]$ and $\hat{\mathrm{J}}_{0}=\left[\mathrm{G}\left(\mathrm{r}_{0}\right) \mathrm{I}\left(\mathrm{r}_{1}\right)-\mathrm{I}\left(\mathrm{r}_{0}\right)\right] /\left[\mathrm{G}\left(\mathrm{r}_{1}\right) \mathrm{G}\left(\mathrm{r}_{0}\right)-1\right]$. QED

In the regular case, the economy has a cyclical equilibrium in which the profit rates $\mathrm{p}_{\mathrm{t}}$ alternate between this $\mathrm{q}_{0}$ and $\mathrm{q}_{1}$. In any period $\mathrm{t}$ when $\mathrm{p}_{\mathrm{t}}=\mathrm{q}_{0}$, investors hire young agents to manage the total aggregate investments $\mathrm{J}_{\mathrm{t}}=\mathrm{I}\left(\mathrm{q}_{0}\right)$. Then in the next period $\mathrm{t}+1$, the profit rate is $\mathrm{p}_{\mathrm{t}+1}=\mathrm{q}_{1}$, and then old agents manage all the investments $\mathrm{I}\left(\mathrm{q}_{1}\right)=\mathrm{G}\left(\mathrm{q}_{1}\right) \mathrm{J}_{\mathrm{t}}$, but there is no new hiring of young agents $J_{t+1}=0$. In this period $t+1$, investors know that the next period in the cycle will have profit rate $\mathrm{p}_{\mathrm{t}+2}=\mathrm{q}_{0}$, and so the regularity condition $\mathrm{Y}\left(\mathrm{q}_{0}\right)=\mathrm{Y}\left(\mathrm{Y}\left(\mathrm{q}_{1}\right)\right)>\mathrm{q}_{1}=\mathrm{p}_{\mathrm{t}+1}$ implies that the current profit rate $\mathrm{p}_{t+1}$ is strictly less than the lowest profit rate $\mathrm{Y}\left(\mathrm{q}_{0}\right)$ at which investors could break even from new hires. Thus, investors do not want to hire any new agents 
in this cycle when the profit rate is $\mathrm{q}_{1}$. But as $\mathrm{q}_{1}<\mathrm{p}^{*}<\mathrm{q}_{0}$, the periods with profit rate $\mathrm{q}_{1}$ are relative boom periods, in which old agents manage more aggregate investment than in the preceding recession period, when all these agents were young.

For our example [4], the regular case applies with an extreme cycle $\left(\mathrm{q}_{0}, \mathrm{q}_{1}\right)$ such that

$$
\begin{aligned}
& \mathrm{q}_{1}=0.141<\mathrm{p}^{*}=0.231<\mathrm{q}_{0}=\mathrm{Y}\left(\mathrm{q}_{1}\right)=0.302 \\
& \mathrm{I}\left(\mathrm{q}_{1}\right) / \mathrm{I}\left(\mathrm{q}_{0}\right)=1.198 / 0.853=1.404=\mathrm{G}\left(\mathrm{q}_{1}\right), \mathrm{q}_{1}<\mathrm{Y}\left(\mathrm{q}_{0}\right)=0.165
\end{aligned}
$$

There exists a cyclical equilibrium in which the profit rates $\mathrm{p}_{t}$ alternate between this $\mathrm{q}_{0}$ and $\mathrm{q}_{1}$. In a recession period when the profit rate is $\mathrm{q}_{0}$, all agents are young newly hired agents, with optimal contracts in which $\mathrm{h}_{0}=1, \mathrm{c}_{0}=0.052, \mathrm{~h}_{1}=1.404, \mathrm{c}_{1}=0.314, \mathrm{c}_{2}=0.768$. Then in the subsequent boom period with profit rate $\mathrm{q}_{1}$, no new agents are hired, but the old agents manage $40 \%$ more aggregate investment than in the preceding period when they were young.

In the dynamic equilibrium shown in Figures 2, 3, and 4, deviations from the steady state p* grow until the economy enters the extreme cycle after period 25. Figure 2 shows the time series of profit rates $\mathrm{p}_{\mathrm{t}}$ for this equilibrium, and Figure 3 is a cob-web diagram showing how the $\mathrm{p}_{\mathrm{t}}=\mathrm{Y}\left(\mathrm{p}_{\mathrm{t}+1}\right)$ equation can cause the profit rates spiral away from the steady state in this dynamic equilibrium. In the early periods when the profit rate is near $\mathrm{p}^{*}$, the magnitude of profit-rate deviations from $\mathrm{p}^{*}$ grow by about $16 \%$ each period, as $-1 / \mathrm{Y}^{\prime}\left(\mathrm{p}^{*}\right)=1 /\left(\delta \mathrm{G}\left(\mathrm{p}^{*}\right)\right)=1.16$. The oscillations grow as long as new agents can be hired in every period, but then, after period 25 , the economy enters the extreme cycle in which new agents are hired only in even-numbered periods. Then for all even $\mathrm{t}>25$, we get $\mathrm{p}_{\mathrm{t}}=\mathrm{q}_{0}=0.302$ and $\mathrm{p}_{\mathrm{t}+1}=\mathrm{q}_{1}=0.141$.

Figure 4 shows the aggregate investment amounts $I\left(\mathrm{p}_{\mathrm{t}}\right)$ that correspond to these profit rates and also shows how this aggregate investment is divided among investments managed by young agents and investments managed by old agents. In this figure, we can see that an extreme inequality of opportunity between generations is spontaneously developing even before the limit cycle is reached. For example, from period 8 to 9 in this equilibrium, aggregate investment $I\left(p_{t}\right)$ increases by less than $3 \%$, but the total investment that is managed by young agents $\mathrm{J}_{\mathrm{t}+1}$ shrinks by almost $23 \%$, as the large cohort of young agents from period 8 crowds out new young agents in period 9. After period 25, in the extreme limit cycle, the aggregate investment amounts alternate between $\mathrm{I}\left(\mathrm{q}_{0}\right)=0.853$ and $\mathrm{I}\left(\mathrm{q}_{1}\right)=1.198$, which are respectively $15 \%$ below and $19 \%$ above the steady state $\mathrm{I}\left(\mathrm{p}^{*}\right)=1.004$.

Such dynamic equilibria that converge to an extreme limit cycle can be found for any 
regular economy with $1<\mathrm{G}\left(\mathrm{p}^{*}\right)<1 / \delta$. See Appendix B for the proof of this fact, which also shows how such dynamic equilibria can be computed, by a construction that works backwards in time from the period before the equilibrium enters the extreme limit cycle.

Fact 2. Suppose that $1<\mathrm{G}\left(\mathrm{p}^{*}\right)<1 / \delta$ and a cycle $\left(\mathrm{q}_{0}, \mathrm{q}_{1}\right)$ exists as in the regular case from Fact 1 . For any initial condition $\mathrm{V}_{0}$ other than $\mathrm{V}^{*}$, there exists an equilibrium that begins with this initial condition and, within finitely many periods, enters the extreme $\left(\mathrm{q}_{0}, \mathrm{q}_{1}\right)$ cycle.

Figure 1 shows the parametric range where we get $\mathrm{G}\left(\mathrm{p}^{*}\right)>1 / \delta$. This case can apply for some $\delta$ when $\theta>0.5$, and it applies for all $\delta$ between 0 and 1 when $\theta>0.807$. Examples of optimal steady-state contracts in this range can be found in the upper rows of Table 1 where $\theta=$ 0.9 or $\theta=0.8$. In this parametric range where $\theta$ is only slightly less than 1 , the agents are close to risk neutral, and optimal contracts have almost completely back-loaded incentives, with the agent getting very little income before retirement. Then with $\mathrm{c}_{0} \approx 0$ and $\mathrm{c}_{1} \approx 0$, the binding incentive constraints yield

$$
\delta \mathrm{c}_{2}{ }^{\theta} \approx(1+\delta)^{1-\theta}\left(\gamma \mathrm{h}_{1}\right)^{\theta} \text { and } \delta^{2} \mathrm{c}_{2}{ }^{\theta} \approx\left(1+\delta+\delta^{2}\right)^{1-\theta}\left(\gamma \mathrm{h}_{0}\right)^{\theta},
$$

and so we get

$$
\delta \mathrm{G}=\delta \mathrm{h}_{1} / \mathrm{h}_{0} \approx\left[\left(1+\delta+\delta^{2}\right) /\left(\delta+\delta^{2}\right)\right]^{1 / \theta-1},
$$

Thus, in this case where $\theta$ is only slightly less than 1 , we can get $\delta G\left(p^{*}\right)>1$ and so $G\left(p^{*}\right)>1 / \delta$.

In this case with $\mathrm{G}\left(\mathrm{p}^{*}\right)>1 / \delta$, condition [3] tells us that we can get cycles around the steady state which dampen over time. To be specific, let us consider an example which differs from our baseline example [4] only in that the utility exponent is $\theta=0.9$, instead of 0.5 . As shown in Table 1 , this example has $\mathrm{G}\left(\mathrm{p}^{*}\right)=2.151>1 / \delta$, with $\delta=0.5$.

\section{[Insert Figure 5 about here]}

Figure 5 shows the aggregate investments for a dynamic equilibrium for an economy with $\theta=0.9$ and all other parameters as in our baseline [4], starting from the worst initial condition $\mathrm{V}_{0}=0$. The cycles of this dynamic equilibrium gradually attenuate toward the steady state, which is locally stable as $\mathrm{G}\left(\mathrm{p}^{*}\right)>1 / \delta$. But although the cycles dampen over time for this example, the worst cycle in equilibrium is actually more extreme than the extreme cycles that we found in Figures 2, 3, and 4. In Figure 5, investment at the peak in period 2 is $49 \%$ greater than at the trough in period 1. In contrast, the unstable dynamics in Figure 4 have cycles in which the 
peak investment $\mathrm{I}\left(\mathrm{q}_{2}\right)$ is $40 \%$ greater than at the trough $\mathrm{I}\left(\mathrm{q}_{1}\right)$. Thus, although the economy with high $\theta$ may be more stable in the long run, its short-term response to shocks may actually be somewhat more volatile than an economy with a lower $\theta$.

Although the alternative case in Fact 1 has not been found for parameters where $\mathrm{G}\left(\mathrm{p}^{*}\right)<1 / \delta$, it can be found for some parameters where $\mathrm{G}\left(\mathrm{p}^{*}\right)>1 / \delta$. With all other parameters as in the baseline [4], when $0.735 \leq \theta \leq 0.793$ we can find pairs $\left(\mathrm{q}_{0}, \mathrm{q}_{1}\right)$ and $\left(\mathrm{r}_{1}, \mathrm{r}_{2}\right)$ that satisfy the local conditions for both the regular and alternative cases in Fact 1:

$$
\begin{aligned}
& \mathrm{q}_{0}=\mathrm{Y}\left(\mathrm{q}_{1}\right), \mathrm{G}\left(\mathrm{q}_{1}\right)=\mathrm{I}\left(\mathrm{q}_{1}\right) / \mathrm{I}\left(\mathrm{q}_{0}\right), \mathrm{q}_{1}<\mathrm{Y}\left(\mathrm{q}_{0}\right)<\mathrm{p}^{*}<\mathrm{q}_{0} ; \\
& \mathrm{r}_{1}=\mathrm{Y}\left(\mathrm{r}_{0}\right)<\mathrm{p}^{*}<\mathrm{r}_{0}=\mathrm{Y}\left(\mathrm{r}_{1}\right), \hat{\mathrm{J}}_{0}+\mathrm{G}\left(\mathrm{r}_{0}\right) \hat{\mathrm{J}}_{1}=\mathrm{I}\left(\mathrm{r}_{0}\right), \hat{\mathrm{J}}_{1}+\mathrm{G}\left(\mathrm{r}_{1}\right) \hat{\mathrm{J}}_{0}=\mathrm{I}\left(\mathrm{r}_{1}\right), \hat{\mathrm{J}}_{0} \geq 0, \hat{\mathrm{J}}_{1} \geq 0 .
\end{aligned}
$$

For example, with $\theta=0.75$ and all other parameters as in the baseline [4], these conditions have solutions with $\mathrm{q}_{1}=0.080, \mathrm{q}_{0}=0.274, \mathrm{r}_{1}=0.123, \mathrm{r}_{0}=0.240$. For this economy, we can find dynamic equilibria that converge to the steady state $\mathrm{p}^{*}=0.183$ from any initial profit rate $\mathrm{p}_{1}$ that is between $r_{1}$ and $r_{0}$; but we can find other dynamic equilibria that converge instead to the extreme $\left(\mathrm{q}_{0}, \mathrm{q}_{1}\right)$ cycle, starting from an initial profit rate that is less than $\mathrm{r}_{1}$ or greater than $\mathrm{r}_{0}$.

Table 1 shows that more risk-averse agents with lower utility exponent $\theta$ tends to get more pre-retirement consumption $c_{0}$ and $c_{1}$, which reduces the growth ratio $G\left(p^{*}\right)$ below $1 / \delta$ when $\theta \leq 0.73$, with other parameters are as in our baseline [4]. In the interval $-1.47 \leq \theta \leq 0.73$ where the steady state is locally unstable, decreasing $\theta$ tends to decrease the amplitude of the extreme cycle even as it increases the rate with which small deviations from the steady state can grow. For example, when we change the utility exponent to $\theta=-1$, keeping all other parameters as above, the equilibrium limit cycle has investment at the peak which is only $5.7 \%$ greater investment at the trough; but small deviations of the profit rate from the steady state $\mathrm{p}^{*}$ tend to grow in magnitude by about $87 \%$ each period, as $1 /\left(\delta \mathrm{G}\left(\mathrm{p}^{*}\right)\right)=1.868$.

\section{[Insert Figure 6 about here]}

Figure 6 shows how the various cycles depend on the utility exponent parameter $\theta$, holding fixed the other parameters $\delta=0.5, \gamma=0.25$, and $I(p)=1.5 \max \{1-p / 0.7,0\}$. The amplitude of the extreme cycle (the difference between its high and low profit rates) becomes small as $\theta$ decreases toward -1.47 , below which the only equilibrium is the steady state. In the interval $0.735 \leq \theta \leq 0.793$, the steady state is locally stable but a stable extreme cycle also exists, and we 
also find an unstable intermediate cycle corresponding to the alternative case described in Fact 1.

\section{Efficiency and stabilization policies}

Our dynamic equilibria induce spontaneous inequalities across generations. In periods when investment is reduced by a scarcity of trusted financial agents, workers and consumers (who have not been explicitly introduced into the model) may suffer, but other generations will enjoy greater welfare in the boom periods. When all generations are considered, however, these dynamic equilibria satisfy a natural efficiency property which can now be described.

Suppose that the investment demand curve $I(p)$ is continuous, has $I(0)$ finite, has some $\overline{\mathrm{p}}>0$ such that $\mathrm{I}(\mathrm{p})=0$ for all $\mathrm{p} \geq \overline{\mathrm{p}}$, and is strictly decreasing for $\mathrm{p}$ between 0 and $\overline{\mathrm{p}}$. Then for any aggregate investment $\mathrm{K}$ between 0 and $\mathrm{I}(0)$ there exists a unique $\mathrm{p}=\mathrm{I}^{-1}(\mathrm{~K})$ between 0 and $\mathrm{I}(0)$ such that $\mathrm{K}=\mathrm{I}(\mathrm{p})$, and we can let

$$
\mathrm{W}(\mathrm{K})=\int_{0}^{\mathrm{K}} \mathrm{I}^{-1}(\mathrm{k}) \mathrm{dk} .
$$

Here $\mathrm{W}(\mathrm{K})$ includes the total cumulative value of increasing investment from 0 to $\mathrm{K}$ when each unit increase is evaluated at its marginal value if there were no more investment. This value $\mathrm{W}(\mathrm{k})$ is greater than the investors' total revenue $\mathrm{I}^{-1}(\mathrm{~K}) \mathrm{K}$ because the investment demand curve is downward sloping. This surplus from the downward slope of $\mathrm{I}(\bullet)$ must correspond to surplus welfare for others individuals who consume output from or supply inputs to the investment activity, and for whom the terms of trade become more favorable as aggregate investment increases. Thus, $\mathrm{W}(\mathrm{K})$ can be interpreted as a measure of aggregate welfare for investors and other consumer or suppliers when total investment is K. (See also Myerson, 2012, pp. 859-860.)

For any planned consumption vector $\mathrm{c}(\mathrm{t})=\left(\mathrm{c}_{0}(\mathrm{t}), \mathrm{c}_{1}(\mathrm{t}), \mathrm{c}_{2}(\mathrm{t})\right)$ offered to agents whose careers start in period $t$, the maximal investments $h_{0}=f_{0}(c(t))$ and $h_{1}=f_{1}(c(t))$ that the agents can incentive-compatibly manage in periods $t$ and $t+1$ are determined by the functions

$$
\begin{aligned}
& \mathrm{f}_{0}(\mathrm{c}(\mathrm{t}))=\left[\left(\mathrm{c}_{0}(\mathrm{t})^{\theta}+\delta \mathrm{c}_{1}(\mathrm{t})^{\theta}+\delta^{2} \mathrm{c}_{2}(\mathrm{t})^{\theta}\right)^{1 / \theta}\left(1+\delta+\delta^{2}\right)^{1-1 / \theta}-\mathrm{c}_{0}(\mathrm{t})\right] / \gamma, \\
& \mathrm{f}_{1}(\mathrm{c}(\mathrm{t}))=\left[\left(\mathrm{c}_{1}(\mathrm{t})^{\theta}+\delta \mathrm{c}_{2}(\mathrm{t})^{\theta}\right)^{1 / \theta}(1+\delta)^{1-1 / \theta}-\mathrm{c}_{1}(\mathrm{t})\right] / \gamma .
\end{aligned}
$$

With these functions characterizing feasible investments as a function of prospective incentive payments, for any given promised constant-equivalent consumption for old agents at period 1, consider the following optimization problem. 


$$
\begin{aligned}
& \operatorname{maximize} \sum_{\mathrm{t} \geq 1} \delta^{\mathrm{t}-1}\left[\mathrm{~W}\left(\mathrm{f}_{0}(\mathrm{c}(\mathrm{t}))+\mathrm{f}_{1}(\mathrm{c}(\mathrm{t}-1))\right)-\mathrm{c}_{0}(\mathrm{t})-\mathrm{c}_{1}(\mathrm{t}-1)-\mathrm{c}_{2}(\mathrm{t}-2)\right] \\
& \text { subject to } \mathrm{c}(\mathrm{t})=\left(\mathrm{c}_{0}(\mathrm{t}), \mathrm{c}_{1}(\mathrm{t}), \mathrm{c}_{2}(\mathrm{t})\right) \geq 0, \forall \mathrm{t},
\end{aligned}
$$$$
\mathrm{c}_{1}(0)^{\theta}+\delta \mathrm{c}_{2}(0)^{\theta}=(1+\delta) \mathrm{V}_{0}{ }^{\theta} \text {. }
$$

(initial promise to cohort 0 )

The objective here is to maximize the sum of discounted welfare $\mathrm{W}$ from investments in each period minus the costs of incentive payments to the agents in each period, when the investments $f_{0}(c(t))+f_{1}(c(t-1))$ that are managed by the two cohorts of agents at period $t$ are the most that they can be trusted to manage with these incentive payments.

Fact 3. An equilibrium $\left\{\mathrm{p}_{\mathrm{t}}, \mathrm{J}_{\mathrm{t}}\right\}$ that satisfies [2] must correspond to an optimal solution $\{c(t)\}$ that maximizes the sum of discounted welfare less cost of agents' incentive pay in [5], with $I\left(p_{t}\right)=f_{0}(c(t))+f_{1}(c(t-1)), J_{t}=f_{0}(c(t))$, and $G\left(p_{t+1}\right) J_{t}=f_{1}(c(t))$ for all $t \geq 1$.

Proof. With $\mathrm{I}\left(\mathrm{p}_{\mathrm{t}}\right)=\mathrm{f}_{0}(\mathrm{c}(\mathrm{t}))+\mathrm{f}_{1}(\mathrm{c}(\mathrm{t}-1))$, the definition of $\mathrm{W}$ implies that

$$
\mathrm{W}^{\prime}\left(\mathrm{f}_{0}(\mathrm{c}(\mathrm{t}))+\mathrm{f}_{1}(\mathrm{c}(\mathrm{t}-1))\right)=\mathrm{I}^{-1}\left(\mathrm{f}_{0}(\mathrm{c}(\mathrm{t}))+\mathrm{f}_{1}(\mathrm{c}(\mathrm{t}-1))\right)=\mathrm{p}_{\mathrm{t}} .
$$

Notice that $\mathrm{W}\left(\mathrm{f}_{0}(\mathrm{c}(\mathrm{t}))+\mathrm{f}_{1}(\mathrm{c}(\mathrm{t}-1))\right)$ is a concave differentiable function of the vectors $\mathrm{c}(\mathrm{t})$ and $c(t-1)$, because $f_{0}$ and $f_{1}$ are concave functions and $\mathrm{W}$ is increasing and concave. So the maximization problem [5] has a concave differentiable maximand. Thus, $\{\mathrm{c}(\mathrm{t})\}$ is an optimal solution of problem [5] if it is an optimal solution of the problem where the objective in [5] is replaced by its local linear approximation:

$$
\sum_{\mathrm{t} \geq 1} \delta^{\mathrm{t}-1}\left[\mathrm{p}_{\mathrm{t}} \mathrm{f}_{0}(\mathrm{c}(\mathrm{t}))+\mathrm{p}_{\mathrm{t}} \mathrm{f}_{1}(\mathrm{c}(\mathrm{t}-1))-\mathrm{c}_{0}(\mathrm{t})-\mathrm{c}_{1}(\mathrm{t}-1)-\mathrm{c}_{2}(\mathrm{t}-2)\right] .
$$

This linear problem can be decomposed into choosing $\mathrm{c}(\mathrm{t})$, for each $\mathrm{t} \geq 1$, to maximize

$$
\mathrm{p}_{\mathrm{t}} \mathrm{f}_{0}(\mathrm{c}(\mathrm{t}))+\delta \mathrm{p}_{\mathrm{t}+1} \mathrm{f}_{1}(\mathrm{c}(\mathrm{t}))-\mathrm{c}_{0}(\mathrm{t})-\delta \mathrm{c}_{1}(\mathrm{t})-\delta^{2} \mathrm{c}_{2}(\mathrm{t})
$$

and choosing $\mathrm{c}(0)$ to maximize $\mathrm{p}_{1} \mathrm{f}_{1}(\mathrm{c}(0))-\mathrm{c}_{1}(0)-\delta \mathrm{c}_{2}(0)$ subject to $\mathrm{c}_{1}(0)^{\theta}+\delta \mathrm{c}_{2}(0)^{\theta}=(1+\delta) \mathrm{V}_{0}{ }^{\theta}$. But these decomposed problems for the various $\mathrm{c}(\mathrm{t})$ are essentially equivalent to the competitive investors' problem [1] without the normalization $\mathrm{h}_{0}=1$, and so the solutions in each case are just multiples of the normalized solutions of [1] . So with $\mathrm{J}_{\mathrm{t}}=\mathrm{f}_{0}(\mathrm{c}(\mathrm{t}))$, we get an optimal solution of [5] when, for each $t \geq 1, c(t)$ is a $\mathbf{J}_{t}$-multiple of an optimal solution of competitive investors' problem [1], and $\mathrm{f}_{1}(\mathrm{c}(0))=\mathrm{V}_{0} \mathrm{H}\left(\mathrm{p}_{1}\right)$. QED

Although Fact 3 implies that our equilibria satisfy an overall efficiency property, the boom/bust cycles can entail severe inequalities of welfare across generations, and policies to 
reduce this inequality could potentially benefit those groups who would suffer in a recession. So let us now consider what kinds of macroeconomic interventions by the government could stabilize this economy when a dynamic equilibrium would take it into a recession.

One natural conjecture is that a credit cycle might be dampened by offering a subsidy for investments in a recession period, financed by bonds to be paid from taxes on production in the subsequent boom period. Such a policy could increase production in the current recession, but it would not stabilize the economy. In a recession period, a scarcity of old agents causes both lower investment and higher recruitment of new young agents, who in turn cause the subsequent boom in the next stage of the credit cycle. A general subsidy for investments in the recession period would increase current investment by increasing the recruitment of young agents, but the increased size and responsibilities of this new cohort of agents would then tend to exacerbate the cycle in the future. Making the cohort larger would tend to crowd out more young agents in the next period, which in turn would cause a deeper recession in the period after that. In fact, to move the future path of the economy toward the steady state, the tax would have to be on investments in the recession period, and the subsidy would be for investments in the subsequent boom period.

For example, consider a recession period in the extreme $\left(\mathrm{q}_{0}, \mathrm{q}_{1}\right)$ cycle for the example in our baseline example [4], where $\theta=0.5, \delta=0.5, \gamma=0.25, \mathrm{I}(\mathrm{p})=1.5 \max \{1-\mathrm{p} / 0.7,0\}$. Suppose that $\mathrm{V}_{0}=0$, so that the economy starts in an extreme recession period starts with no old agents. Recall that, in the extreme cycle for this example, aggregate investment in recession periods $\mathrm{I}\left(\mathrm{q}_{0}\right)$ is $15 \%$ below steady state $\mathrm{I}\left(\mathrm{p}^{*}\right)$, but investment in boom periods $\mathrm{I}\left(\mathrm{q}_{1}\right)$ is $19 \%$ above steady state.

Now consider introducing a net tax $\tau_{t}$ on investments in periods $t=1,2$, where a subsidy corresponds to a negative tax. Let $\mathrm{p}_{\mathrm{t}}$ denote the pre-tax profit rate in period $\mathrm{t}$, which will be on the given investment-demand curve. Suppose that the goal of stabilization is to have the economy in the steady-state path from period 3 onwards, and so we require

$$
\mathrm{p}_{3}=\mathrm{p}^{*} \text { and } \mathrm{J}_{2}=\mathrm{J}^{*}=\mathrm{I}\left(\mathrm{p}^{*}\right) /\left(\mathrm{G}\left(\mathrm{p}^{*}\right)+1\right) \text {. }
$$

To have recruiting of agents in periods 1 and 2, we must have

$$
\mathrm{p}_{1}-\tau_{1}=\mathrm{Y}\left(\mathrm{p}_{2}-\tau_{2}\right) \text { and } \mathrm{p}_{2}-\tau_{2}=\mathrm{Y}\left(\mathrm{p}_{3}\right)
$$

So with $\mathrm{Y}\left(\mathrm{p}^{*}\right)=\mathrm{p}^{*}$, we get $\mathrm{p}_{1}-\tau_{1}=\mathrm{p}_{2}-\tau_{2}=\mathrm{p}^{*}$. That is, investments in each period must have expected after-tax profit rates (before paying the agents) that are just equal to the steady-state rate $\mathrm{p}^{*}$. Then with $\mathrm{V}_{0}=0$ and the given investment-demand function I, we get 


$$
0+\mathrm{J}_{1}=\mathrm{I}\left(\mathrm{p}_{1}\right)=\mathrm{I}\left(\mathrm{p}^{*}+\tau_{1}\right), \mathrm{G}\left(\mathrm{p}_{2}-\tau_{2}\right) \mathrm{J}_{1}+\mathrm{J}_{2}=\mathrm{G}\left(\mathrm{p}^{*}\right) \mathrm{J}_{1}+\mathrm{J}^{*}=\mathrm{I}\left(\mathrm{p}_{2}\right)=\mathrm{I}\left(\mathrm{p}^{*}+\tau_{2}\right) .
$$

Finally, budget balancing requires

$$
\tau_{1} \mathrm{I}\left(\mathrm{p}_{1}\right)+\delta \tau_{2} \mathrm{I}\left(\mathrm{p}_{2}\right)=0
$$

These equations have the solution $\tau_{1}=0.199, \tau_{2}=-0.168, \mathrm{~J}_{1}=0.577$. So a $19.9 \%$ tax on investments in the recession period 1 and a balanced $16.8 \%$ subsidy on investments in the boom period 2 can put the economy in the steady-state from period 3 onwards, but only after period-1 investment $\mathrm{I}\left(\mathrm{p}_{1}\right)$ is $42 \%$ below steady state $\mathrm{I}\left(\mathrm{p}^{*}\right)$, and period- 2 investment $\mathrm{I}\left(\mathrm{p}_{2}\right)$ is $36 \%$ above steady state. These fluctuations are much bigger than the $\left(\mathrm{q}_{0}, \mathrm{q}_{1}\right)$ cycle without stabilization. So this plan is stabilization by extreme austerity in period 1 .

For a stabilization policy that yields a less extreme initial depression, we may consider instead subsidizing investments in period 1 by agents who will not go on to manage any investments in period 2. It is, after all, the lack of such investments that causes the recession. Private investors will not undertake such investments with management by short-term agents without a subsidy, but the government could sponsor such investments. As such investments are considered here with the goal of stabilizing the economy, we may refer to these investments with an inefficient short-term management contracts as "Keynesian" investments.

So in the same example as before, suppose that some amount $\mathrm{K}_{1}$ of Keynesian investment that is financed by a tax $\tau_{1}$ on all other investment in period 1. The minimal agency cost for oneperiod management contracts is $\mathrm{Y}(0)$ per unit investment. This minimal cost is achieved by using young agents who can enjoy high consumption in the next two periods if their project succeeds in period 1, even though they will not manage investments in period 2 . Then the budget-balance condition is

$$
\tau_{1}\left(\mathrm{I}\left(\mathrm{p}_{1}\right)-\mathrm{K}_{1}\right)=\left(\mathrm{Y}(0)-\mathrm{p}_{1}\right) \mathrm{K}_{1} .
$$

If the goal is to put the economy in the steady state in period 2, then we must have $\mathrm{p}_{2}=\mathrm{p}^{*}$ and $J_{1}=J^{*}$. The investment-demand curve with $V_{0}=0$ gives us $I\left(p_{1}\right)=0+J_{1}+K_{1}$. The condition for competitive hiring of young agents $J_{1}>0$ is $p_{1}-\tau_{1}=Y\left(p_{2}\right)=p^{*}$. Thus we need

$$
\mathrm{I}\left(\mathrm{p}^{*}+\tau_{1}\right)=\mathrm{J}^{*}+\mathrm{K}_{1} \text { and } \tau_{1} \mathrm{I}\left(\mathrm{p}^{*}+\tau_{1}\right)=\left(\mathrm{Y}(0)-\mathrm{p}^{*}\right) \mathrm{K}_{1} \text {. }
$$

A solution can always be found with $0<\tau_{1}<Y(0)-p^{*}$. For our example [4], we have $\mathrm{Y}(0)=0.382$, and these equations have solution $\tau_{1}=0.083, \mathrm{~K}_{1}=0.457$. Thus, Keynesian investment financed by current taxes can put this economy in the steady state after one period of recession in which aggregate investment $\mathrm{I}\left(\mathrm{p}_{1}\right)$ is $18 \%$ below steady state $\mathrm{I}\left(\mathrm{p}^{*}\right)$. 
Spreading the cost of the Keynesian investment over more periods could bring the economy to steady state with a less severe initial recession. For our example [4], if the cost of Keynesian investment in period 1 were paid by taxes in periods 1 and 2, then the economy could be put into steady state at period 3 with investment tax rates $\tau_{1}=\tau_{2}=0.067$ to finance $K_{1}=$ 0.576. This Keynesian investment $K_{1}$ and tax rate $\tau_{1}=\tau_{2}=\tau$ satisfy the equations

$$
\begin{aligned}
& \left(Y(0)-p^{*}\right) K_{1}=\tau\left[\mathrm{I}\left(\mathrm{p}^{*}+\tau\right)+\delta \mathrm{I}\left(\mathrm{p}^{*}+\tau\right)\right], \\
& \mathrm{I}\left(\mathrm{p}^{*}+\tau\right)=\mathrm{J}^{*}+\mathrm{G}\left(\mathrm{p}^{*}\right)\left[\mathrm{I}\left(\mathrm{p}^{*}+\tau\right)-\mathrm{K}_{1}\right] .
\end{aligned}
$$

So this policy would stabilize the economy after a two-period recession in periods 1 and 2, when aggregate investment would be $14.3 \%$ below steady state, which is slightly less severe than the trough of the extreme cycle without stabilization.

Finally, let us consider one other class of stabilization policies. Instead of subsidizing some special Keynesian investments by taxing unregulated private investments, the government might simply regulate all investment in period 1 . For macroeconomic stabilization, the government might regulate all the contracts that investors offer young agents in period 1 , to restrict the growth of responsibilities in period 2 that can be promised to agents who manage successful investments in period 1.

In such contract regulation, let $\eta$ denote the regulatory upper bound on the size of investment that an agent can be asked to manage when old in period 2, per unit managed by the agent when young in period 1 . Then the standard optimal contracting problem for investors who hire young agents in period 1 with $\mathrm{h}_{0}=1$ is to choose $\left(\mathrm{c}_{0}, \mathrm{~h}_{1}, \mathrm{c}_{1}, \mathrm{c}_{2}\right)$ to

$$
\begin{aligned}
& \operatorname{maximize} \mathrm{h}_{0} \mathrm{p}_{1}+\delta \mathrm{h}_{1} \mathrm{p}_{2}-\mathrm{c}_{0}-\delta \mathrm{c}_{1}-\delta^{2} \mathrm{c}_{2} \\
& \text { subject to }\left(\mathrm{h}_{0}, \mathrm{c}_{0}, \mathrm{~h}_{1}, \mathrm{c}_{1}, \mathrm{c}_{2}\right) \geq 0, \mathrm{~h}_{0}=1, \mathrm{~h}_{1} \leq \eta \mathrm{h}_{0}, \\
& \left(\mathrm{c}_{1}{ }^{\theta}+\delta \mathrm{c}_{2}{ }^{\theta}\right) / \theta \geq(1+\delta)\left[\left(\mathrm{c}_{1}+\gamma \mathrm{h}_{1}\right) /(1+\delta)\right]^{\theta} / \theta, \\
& \left(\mathrm{c}_{0}{ }^{\theta}+\delta \mathrm{c}_{1}{ }^{\theta}+\delta^{2} \mathrm{c}_{2}{ }^{\theta}\right) / \theta \geq\left(1+\delta+\delta^{2}\right)\left[\left(\mathrm{c}_{0}+\gamma \mathrm{h}_{0}\right) /\left(1+\delta+\delta^{2}\right)\right]^{\theta} / \theta .
\end{aligned}
$$

For investors to break even under these regulated contracts, this contracting problem must have optimal value 0 ; and this condition can determine $p_{1}$ from $p_{2}$ for any given $\eta$. When the recession period 1 has no old agents $\left(\mathrm{V}_{0}=0\right)$ and the $\eta$ regulatory constraint binds, the cohort of young agents who are hired under such contracts to manage $I\left(p_{1}\right)$ in period 1 will be expected to manage $\eta \mathrm{I}\left(\mathrm{p}_{1}\right)$ in period 2 . To put the economy in steady state in period 2 , we need $\mathrm{p}_{2}=\mathrm{p}^{*}$ and $\mathrm{J}_{2}=\mathrm{J}^{*}$, and so 


$$
\eta \mathrm{I}\left(\mathrm{p}_{1}\right)=\mathrm{I}\left(\mathrm{p}^{*}\right)-\mathrm{J}^{*} .
$$

Thus, to stabilize the economy, the regulatory parameter $\eta$ must be chosen so that this equation is satisfied with the $\mathrm{p}_{1}$ that yields optimal value 0 in the contracting problem with $\mathrm{p}_{2}=\mathrm{p}^{*}$. For our example [4], these conditions have the solution $\eta=0.736$ and $\mathrm{p}_{1}=0.297$. So this policy could stabilize this economy after a one-period recession in period 1 when aggregate investment $\mathrm{I}\left(\mathrm{p}_{1}\right)$ is $14.0 \%$ below the steady state $\mathrm{I}\left(\mathrm{p}^{*}\right)$.

\section{Extensions to the case where agents serve more than two periods}

Similar results have been found in Myerson (2012) for the case where risk-neutral agents manage investments in more than two periods. While the greater complexity of nonlinear utility functions has prevented me from fully solving such multi-period models here, I can show that at least some of our results about the local instability of the steady state can be extended to models where agents serve many periods.

Suppose now that an agent whose career starts in period t can manage investments in the $\mathrm{n}$ periods from $\mathrm{t}$ to $\mathrm{t}+\mathrm{n}-1$, and then has one period of retirement at $t+n$. Let $\mathrm{c}_{\mathrm{s}}$ and $\mathrm{h}_{\mathrm{s}}$ denote the agent's paid consumption and investment responsibilities at time $\mathrm{t}+\mathrm{s}$. In the steady state, where

profit rates are some constant $\mathrm{p}^{*}$, investors who plan make payments worth some given value $\mathrm{C}$ to the agent would want to use an efficient incentive plan where $\left(\mathrm{h}_{0}, \ldots, \mathrm{h}_{\mathrm{n}-1}, \mathrm{c}_{0}, \ldots, \mathrm{c}_{\mathrm{n}}\right)$ solve

$$
\begin{aligned}
& \operatorname{maximize} \sum_{\mathrm{s} \in\{0, \ldots, \mathrm{n}-1\}} \delta^{\mathrm{s}} \mathrm{h}_{\mathrm{s}} \\
& \text { subject to }\left(\mathrm{h}_{0}, \ldots, \mathrm{h}_{\mathrm{n}-1}, \mathrm{c}_{0}, \ldots, \mathrm{c}_{\mathrm{n}}\right) \geq 0, \quad \sum_{\mathrm{s} \in\{0, \ldots, \mathrm{n}\}} \delta^{\mathrm{s}} \mathrm{c}_{\mathrm{s}}=\mathrm{C}, \quad \text { and } \\
& \left(\sum_{\mathrm{r} \in\{\mathrm{s}, \ldots, \mathrm{n}\}} \delta^{\mathrm{r}-\mathrm{s}}\right)^{1-\theta}\left(\mathrm{c}_{\mathrm{s}}+\gamma \mathrm{h}_{\mathrm{s}}\right)^{\theta} / \theta \leq \sum_{\mathrm{r} \in\{\mathrm{s}, \ldots, \mathrm{n}\}} \delta^{\mathrm{r}-\mathrm{s}}\left(\mathrm{c}_{\mathrm{r}}\right)^{\theta} / \theta, \quad \forall \mathrm{s} \in\{0, \ldots, \mathrm{n}-1\} .
\end{aligned}
$$

Let $\left(\mathrm{h}_{0}, \ldots, \mathrm{h}_{\mathrm{n}-1}, \mathrm{c}_{0}, \ldots, \mathrm{c}_{\mathrm{n}}\right)$ denote an optimal solution to this problem [7] when the parameter $\mathrm{C}$ is adjusted so that the linearly-rescaled solution has $\mathrm{h}_{0}=1$. The steady-state profit rate $\mathrm{p}^{*}$ at which investors could just break even is then

$$
\mathrm{p}^{*}=\mathrm{C} /\left(\sum_{\mathrm{s} \in\{0, \ldots, \mathrm{n}-1\}} \delta^{\mathrm{s}} \mathrm{h}_{\mathrm{s}}\right) .
$$

In the steady state, the aggregate investment for a new cohort of young agents in each period $t$ is $\mathrm{J}^{*}=\mathrm{I}\left(\mathrm{p}^{*}\right) \mathrm{h}_{0} /\left(\mathrm{h}_{0}+\mathrm{h}_{1}+\ldots+\mathrm{h}_{\mathrm{n}-1}\right)$, and then they manage $\mathrm{h}_{\mathrm{s}} \mathrm{J}^{*}$ in each period $\mathrm{t}+\mathrm{s}$ for $\mathrm{s} \in\{0, \ldots, \mathrm{n}-1\}$.

Now, assuming an economy that was in steady state, let us try to analyze what would 
happen if some temporary unanticipated shock caused the size of some cohorts' responsibilities to deviate slightly from steady state in a few (less than $\mathrm{n}$ ) time periods ending at some period $\mathrm{T}$. For any period t during the shock or thereafter, let $\mu_{\mathrm{t}}=\mathrm{J}_{\mathrm{t}}-\mathrm{J}^{*}$ denote the deviation of young agents' responsibilities from steady state, and let $\pi_{\mathrm{t}}=\mathrm{p}_{\mathrm{t}}-\mathrm{p}^{*}$ denote the deviation of the profit rate from steady state. Let us assume a nonzero shock $\mu_{\mathrm{T}} \neq 0$ at time $\mathrm{T}$, at least. We may say that the small shock has small consequences if, in equilibrium after T, profit rates will stay close enough to $\mathrm{p}^{*}$ that investors will keep hiring new agents in every period with an optimal incentive plan that is close to the solution of [7].

Our first question is, if the deviations $\mu_{\mathrm{t}}$ during the shock are small enough, can the steady-state profit rate $\mathrm{p}^{*}$ be maintained thereafter? This continuation of $\mathrm{p}^{*}$ would require that, in each period after $\mathrm{T}$, the deviations from steady-state investment responsibilities of different cohorts must always cancel out. With profit rates staying at $\mathrm{p}^{*}$, the solution to problem [7] remains the optimal contract at every period after T. So the steady-state profit rate $\mathrm{p}^{*}$ can be maintained only if the $\mu_{\mathrm{t}}$ deviation satisfy

$$
\sum_{\mathrm{s} \in\{0,1, \ldots, \mathrm{n}-1\}} \mathrm{h}_{\mathrm{s}} \mu_{\mathrm{t}-\mathrm{s}}=0, \forall \mathrm{t}>\mathrm{T} .
$$

Given any vector of shocks $\left(\mu_{\mathrm{T}-(\mathrm{n}-1)}, \ldots, \mu_{\mathrm{T}}\right), \mu_{\mathrm{t}}$ is determined for all $\mathrm{t}>\mathrm{T}$ by these linear difference equations [8]. If, for some initial shock vectors, these linear equations [8] have solutions that grow without bound, then we can find arbitrary small shocks that would compel the profit rate to deviate from the steady state. Such divergence can be shown when the following ( $\mathrm{n}-1)$-degree polynomial in $\mathrm{x}$ has any real or complex root with magnitude greater than one:

$$
\sum_{\mathrm{s} \in\{0,1, \ldots, \mathrm{n}-1\}} \mathrm{h}_{\mathrm{s}} \mathrm{x}^{\mathrm{n}-1-\mathrm{s}}=0 \text { for some complex number } \mathrm{x} \text { such that }|\mathrm{x}|>1 \text {. }
$$

For the case of $n=2$ (with all $h_{s}>0$ and $h_{0}=1$ ), this divergence condition [9] is satisfied when $\mathrm{G}\left(\mathrm{p}^{*}\right)=\mathrm{h}_{1}>1$.

Suppose now that condition [9] guarantees that arbitrarily small shocks can force profit rates to deviate from the steady state $\mathrm{p}^{*}$. We now ask whether the profit rates after such small shocks may at least be kept within some arbitrarily small neighborhood of $\mathrm{p}^{*}$. With sufficiently small profit-rate deviations $\pi_{\mathrm{t}}$, the solution to [7] would remain approximately optimal for investors hiring new agents at every period t. So by the envelope theorem, the local first-order condition to maintain zero expected profits for investors from hiring new agents at any period 
$\mathrm{t}>\mathrm{T}$ would be

$$
\sum_{\mathrm{s} \in\{0,1, \ldots, \mathrm{n}-1\}} \mathrm{h}_{\mathrm{s}} \delta^{\mathrm{s}} \pi_{\mathrm{t}+\mathrm{s}}=0, \forall \mathrm{t}>\mathrm{T}
$$

Given any vector of shocks $\left(\pi_{\mathrm{T}+1}, \ldots, \pi_{\mathrm{T}+\mathrm{n}-1}\right), \pi_{\mathrm{t}+\mathrm{n}}$ can be determined for all $\mathrm{t}>\mathrm{T}$ by these linear difference equations [10] (with $\delta^{\mathrm{n}-1} \mathrm{~h}_{\mathrm{n}-1}>0$ ). Thus, divergence of profit rates from the neighborhood of the steady state can be proven if all nonzero solutions to these linear difference equations in $\pi$ become unbounded over time. Such divergence can be shown when all real and complex roots of the following ( $\mathrm{n}-1)$-degree polynomial in $\mathrm{x}$ have magnitudes greater than one:

$$
|x|>1 \text { for every complex number } x \text { such that } \sum_{s \in\{0,1, \ldots, n-1\}} h_{s} \delta^{s} x^{s}=0 \text {. }
$$

For the case of $n=2$, this divergence condition [11] is satisfied when $\delta G\left(p^{*}\right)=\delta h_{1}<1$.

\section{[Insert Figure 7 about here]}

Figure 7 shows the optimal investment responsibilities in a solution of [7] for the case of when agents can manage investments in $n=10$ periods, their utility exponent is $\theta=0.5$, the moralhazard coefficient is $\gamma=0.25$, and the discount factor is $\delta=0.8706=0.25^{(1 / n)}$, so that an agent's initial discounting of payoffs from retirement is still $\delta^{\mathrm{n}}=0.25$ (as in our previous benchmark case with $n=2$ and $\delta=0.5$ ). Investment responsibilities at each period in this optimal contract are

$$
\left(\mathrm{h}_{0}, \mathrm{~h}_{1}, \ldots \mathrm{h}_{9}\right)=(1,1.302,1.628,1.957,2.259,2.492,2.6,2.509,2.127,1.338) .
$$

This solution corresponds to a steady-state profit rate $\mathrm{p}^{*}=0.0409$. An agent's responsibilities are expected to increase steadily in the first seven periods, but then the responsibilities decrease in the last three periods before retirement. It can be shown that the divergence conditions [9] and [11] are both satisfied for this example. (The largest roots of [9] are 0.264 $\pm 1.015 i$, which have magnitude 1.042, and the smallest roots of [11] are $0.770 \pm 0.712 \mathrm{i}$, which have magnitude 1.049.) Thus, the steady state in this example is locally unstable, in the sense that arbitrarily small shocks near the steady state must eventually lead to dynamic equilibrium paths that differ significantly from the steady state, in the sense investors are not willing to hire new agents under incentive contracts that are even close to the steady-state solutions of [7].

This local instability of the steady state can also be verified for examples with $\theta$ from -0.4 to 0.7 , keeping the other parameters $(n, \delta, \gamma)$ fixed as above. If we increase the number of periods to $n=100$, keeping $\delta^{n}=0.25$ with $\theta=0.5$ and $\gamma=0.25$, the optimal incentive plan [7] yields an path of investment responsibilities over an agent's career that looks similar to Figure 7 (with a 
steady state profit rate $\mathrm{p}^{*}=0.004$ per period), and the same local instability of the steady state can be verified also for this example.

\section{A related model with risk-neutral agents but different discount factors}

To understand the effects of risk aversion in the above model, in this section let us consider a related model where agents are risk neutral $(\theta=1)$, but let us now allow that agents may have a discount factor $\delta_{1}$ that is different from investors' discount factor $\delta_{0}$. In this section let us also assume that agents cannot save but must consume all income in the period that it is received. As above, an agent could steal a fraction $\gamma$ of the amount invested. So when a young agent is hired to manage investments in periods $t$ and $t+1$, with profit rates $p_{t}$ and $p_{t+1}$, the investors want to choose the agent's investments $h_{s}$ and consumption allowances $c_{s}$ for each period $t+s$ to solve the following constrained optimization problem:

$$
\begin{aligned}
& \operatorname{maximize} \mathrm{h}_{0} \mathrm{p}_{\mathrm{t}}+\delta_{0} \mathrm{~h}_{1} \mathrm{p}_{\mathrm{t}+1}-\mathrm{c}_{0}-\delta_{0} \mathrm{c}_{1}-\delta_{0}{ }^{2} \mathrm{c}_{2} \\
& \text { subject to }\left(\mathrm{h}_{0}, \mathrm{c}_{0}, \mathrm{~h}_{1}, \mathrm{c}_{1}, \mathrm{c}_{2}\right) \geq 0, \mathrm{~h}_{0}=1, \\
& \mathrm{c}_{1}+\delta_{1} \mathrm{c}_{2} \geq \mathrm{c}_{1}+\gamma \mathrm{h}_{1}, \\
& \mathrm{c}_{0}+\delta_{1} \mathrm{c}_{1}+\delta_{1}{ }^{2} \mathrm{c}_{2} \geq \mathrm{c}_{0}+\gamma \mathrm{h}_{0} .
\end{aligned}
$$

(incentive constraint at $t+1$ )

(incentive constraint at $t$ )

With risk neutrality, this optimal contracting problem becomes a simple linear programming problem which must have a corner solution. For profit rates satisfying

$$
\gamma \delta_{0} / \delta_{1} \geq \mathrm{p}_{\mathrm{t}+1} \geq \max \left\{0, \gamma \delta_{0} / \delta_{1}-\gamma\right\},
$$

the optimal solution is to fully back-load the agent's payments and have

$$
\mathrm{h}_{0}=1, \mathrm{c}_{0}=0, \mathrm{c}_{1}=0, \mathrm{c}_{2}=\gamma / \delta_{1}^{2} \text {, and } \mathrm{h}_{1}=1 / \delta_{1} \text {. }
$$

(With $\mathrm{p}_{\mathrm{t}+1}$ in this interval, the optimality of this solution can be verified by standard KuhnTucker conditions with Lagrange multipliers $\lambda_{1}=\delta_{0} \mathrm{p}_{\mathrm{t}+1} / \gamma$ and $\lambda_{0}=\left(\delta_{0} / \delta_{1}\right)^{2}-\left(\delta_{0} / \delta_{1}\right) \mathrm{p}_{\mathrm{t}+1} / \gamma$ for the binding incentive constraints at periods $t+1$ and $t$.) The upper bound on $p_{t+1}$ here implies that investors cannot profit from hiring old agents for just one period at time $t+1$. The lower bound implies that investors who have promised a position worth $\mathrm{u}_{1}$ to an old agent in period $\mathrm{t}+1$ would want to ask the agent to manage $h_{1}=u_{1} / \gamma$ for a payment of $u_{1} / \delta_{1}$ in period $t+2$, rather than pay the $\mathrm{u}_{1}$ debt immediately at $\mathrm{t}+1$. We find equilibrium profit rates in this interval.

At this optimal solution, the investors' optimal value is

$$
\mathrm{h}_{0} \mathrm{p}_{\mathrm{t}}+\delta_{0} \mathrm{~h}_{1} \mathrm{p}_{\mathrm{t}+1}-\mathrm{c}_{0}-\delta_{0} \mathrm{c}_{1}-\delta_{0}^{2} \mathrm{c}_{2}=\mathrm{p}_{\mathrm{t}}+\left(\delta_{0} / \delta_{1}\right) \mathrm{p}_{\mathrm{t}+1}-\gamma\left(\delta_{0} / \delta_{1}\right)^{2}
$$


For this solution to apply in a steady-state equilibrium where $\mathrm{p}_{t}=\mathrm{p}_{\mathrm{t}+1}=\mathrm{p}^{*}$, this optimal value must be 0 for competitive investors when they hire a new agent at time $t$, and so we get

$$
\mathrm{p}^{*}=\gamma\left(\delta_{0} / \delta_{1}\right)^{2} /\left(1+\delta_{0} / \delta_{1}\right)
$$

It can be verified that this steady-state $\mathrm{p}^{*}$ strictly satisfies the above bounds on $\mathrm{p}_{\mathrm{t}+1}$.

Thus, for equilibria in an interval around the steady state, the zero-profit equilibrium condition for competitive investors to hire new agents in any period $t$ is

$$
\mathrm{p}_{\mathrm{t}}+\left(\delta_{0} / \delta_{1}\right) \mathrm{p}_{\mathrm{t}+1}=\gamma\left(\delta_{0} / \delta_{1}\right)^{2}=\mathrm{p}^{*}+\left(\delta_{0} / \delta_{1}\right) \mathrm{p}^{*}
$$

That is, in any period $\mathrm{t}$ when investors are willing to hire new agents under the optimal twoperiod contract, we must have

$$
\mathrm{p}_{\mathrm{t}+1}-\mathrm{p}^{*}=-\left(\delta_{1} / \delta_{0}\right)\left(\mathrm{p}_{\mathrm{t}}-\mathrm{p}^{*}\right)
$$

This equation [14] tells us that, in the region near the steady state where new agents are hired every period, the dynamics depend critically on the ratio $\delta_{1} / \delta_{0}$. When $\delta_{1}=\delta_{0}$, we can get constant cycling around the steady state, with new agents hired every period (as in the previous paper of Myerson, 2012). If $\delta_{1}<\delta_{0}$ (agents less patient than investors) then deviations of $\mathrm{p}_{\mathrm{t}}$ from $\mathrm{p}^{*}$ tend to shrink over time, and so the economy is dynamically stable. But if $\delta_{1}>\delta_{0}$ (agents are more patient than investors) then the steady state must be locally unstable, because small deviations from $\mathrm{p}^{*}$ must grow. Such equilibria are shown in Figures 8 and 9, for an example where all parameters are as in the baseline case [4] (with $\gamma=0.25$ and $\mathrm{I}(\mathrm{p})=$ $1.5 \max \{1-\mathrm{p} / 0.7,0\})$ except that now $\theta=1$ and the risk-neutral agents' discount factor is changed to be either smaller $\left(\delta_{1}=0.4\right.$ in Figure 8$)$ or larger $\left(\delta_{1}=0.6\right.$ in Figure 9$)$ than the investors' fixed discount factor $\delta_{0}=0.5$.

\section{[Insert Figures 8 and 9 about here]}

It may at first seem puzzling that making the agents more patient can cause dynamic instability. Under the optimal back-loaded contracts, agents must be motivated by late-career rewards, which become less costly (for any given initial responsibilities) as agents become more patient. Indeed, we can see in Figures 8 and 9 that more patient agents (with larger $\delta_{1}$ ) are associated with lower equilibrium profit rates. In Figure 8 with less patient agents, the steadystate profit rate (approximated on the right) is $\mathrm{p}^{*}=0.174$, and the highest profit rate (starting from the worst initial condition $\mathrm{V}_{0}=0$ on the left) is $\mathrm{p}_{\max }=0.313$. In Figure 9 with more patient agents, the steady-state profit rate (approximated on the left) is $\mathrm{p}^{*}=0.095$, and the highest profit 
rate (in the recessions of the extreme cycle on the right) is $\mathrm{p}_{\max }=0.174$.

To understand the source of the dynamic instability with more patient agents here, we must recognize where the ratios of discount factors came from in equations [13] and [14]. In the equilibrium expected-profit equation [13], the factor $\delta_{0}$ represents the investors' discounting of future profits. The factor $1 / \delta_{1}$ in equation [13] represents the expected growth of an agent's responsibilities in her second period compared to the first period. That is, in the optimal backloaded contract, the expected investment responsibility $\mathrm{h}_{1}$ of an agent in her second period is $1 / \delta_{1}$ times the agent's investment responsibility $\mathrm{h}_{0}$ in her first period. So making $\delta_{1}$ larger means that a young agent's responsibilities do not need to be so much smaller than her expected older responsibilities, as her expected discounted value of the late career reward which motivates her good behavior in both periods is less discounted when she is young.

When $\delta_{1}=\delta_{0}$, the investors' discounting of the future exactly cancels out the expected growth of the agent's responsibilities, so that profit rates from both periods contribute equally to the investors' expected discounted value of profits from their contract with the agent. (Cycles with $\delta_{1}=\delta_{0}=0.5$ are shown in gray in Figure 2.)

But when the agent is more patient, with $\delta_{1}>\delta_{0}$, the investors' discounting of the future becomes a stronger effect than the agent's expected growth of responsibilities, and so the investors' expected discounted value of profits in [13] becomes more sensitive to the current profit rate $\mathrm{p}_{\mathrm{t}}$ than to the future profit rate $\mathrm{p}_{\mathrm{t}+1}$. So with $\delta_{1}>\delta_{0}$, in a dynamic equilibrium with rational expectations, any deviation of $\mathrm{p}_{\mathrm{t}}$ from the steady-state $\mathrm{p}^{*}$ must be balanced by a larger deviation of $\mathrm{p}_{\mathrm{t}+1}$ in the opposite direction. Thus, with $\delta_{1}>\delta_{0}$, oscillating deviations from the steady state must grow until we reach periods when investors are not willing to hire any new young agents, so that equations [13] and [14] no longer apply. Increasing $\delta_{1}$ would increase the rate at which the oscillations amplify around the steady state, but it would also decrease the amplitude of the limit cycle to which the oscillations converge.

Now let us return to the model with risk-averse agents that is the main focus of this paper. Risk aversion makes the optimal contracting problem nonlinear, and so we no longer get a corner solution with full back-loading of rewards. In our model with risk-averse agents, the optimal incentive plan pays them a positive amount $c_{0}$ and $c_{1}$ in each period when they have investment responsibilities. But less back-loading of rewards can imply that there is also less increase of agents' expected responsibilities in going from young to old. Thus, like an increase in agents' 
patience, making the agents risk averse can reduce their expected growth of responsibilities from young to old. And when agents' expected responsibility-growth ratios become smaller, investors become relatively less sensitive to future profit rates, and so they need greater counter-deviations in future profit rates to compensate for any deviation in the present. Thus, risk aversion can yield the same kind of dynamic instability that we found, in this section, with risk-neutral agents who are more patient than investors.

\section{Conclusions}

From the most general perspective, we should recognize the basic fact that employers regularly need to make commitments of long-term relationships with agents whom they hire to fill certain kinds of important responsible positions. Any new hiring into such positions then must depend on long-term estimates of future returns in the economy, and the existing commitments that employers have previously made with mid-career agents must be considered as part of the dynamic state of the economy at any point in time. Clearly such long-term employment relationships have the potential to greatly complicate economic dynamics. This paper and its predecessor (Myerson, 2012) have considered simple models to show how basic natural assumptions about such long-term employment relationships can imply persistent aggregate fluctuations in a dynamic economy. The key insight underlying these results is that, unlike standard assumptions of depreciation in capital theory, standard assumptions in agency theory can make a long-term employment relationship an investment that becomes more productive over time, as an agent's responsibilities may increase with seniority.

We have considered models of a simple dynamic economy in which investors can only invest through risk-averse financial agents who are subject to moral hazard. Because of this moral hazard, optimal incentive contracts typically involve substantial late-career rewards for good service, and so the agents must have long-term relationships with investors. These relationships can create complex macroeconomic dynamics in which agents' contractual positions or wealth form the state of this dynamic system.

In the recessions of our models, productive investment is reduced by a scarcity of trusted financial intermediaries. Competitive recruitment of new financial agents cannot fully remedy such undersupply, because agents can be efficiently hired only with long-term contracts in which their responsibilities are expected to grow during their careers. So a large adjustment to reach 
steady-state financial capacity in one period would create oversupply in future periods.

For new agents to be hired each period, low profit rates must be followed be higher expected rates in a later period, which must be followed in turn by lower expected rates. Optimal contracts for risk-averse agents typically include some consumption rewards earlier in the agent's career, in addition to the large late-career rewards, and so agents may have less expected growth of responsibilities than in the corresponding risk-neutral case. But this effect can actually make the dynamic economy even less stable, in the sense that small deviations from steady state tend to amplify over time. Thus, in the absence of any fiscal policies for macroeconomic stabilization, the economy can spontaneously develop large cyclical inequalities across generations.

\section{Appendix A. Computation of optimal contracts}

We are considering the problem of designing an optimal incentive contract for an agent who is young in period $t$, can manage investments also as an old agent in period $t+1$, and will then retire in period $t+2$. This problem can be decomposed into a young-agent incentive problem and old-agent incentive problem, if we add a variable $\mathrm{v}_{1}$ that measures the young agent's anticipated future welfare in periods $t+1$ and $t+2$. So let $u$ s define $v_{1}$ to be the constantequivalent consumption that would yield the same utility for the agent in periods $t+1$ and $t+2$, satisfying the equation

$$
(1+\delta) \mathrm{v}_{1}{ }^{\theta} / \theta=\left(\mathrm{c}_{1}{ }^{\theta}+\delta \mathrm{c}_{2}{ }^{\theta}\right) / \theta
$$

where $c_{1}$ and $c_{2}$ denote the agent's anticipated consumption in periods $t+1$ and $t+2$. Then the decision variables in the young-agent incentive problem are the investment $\mathrm{h}_{0}$ managed by the young agent in period $\mathrm{t}$, the consumption $\mathrm{c}_{0}$ for the young agent in period $\mathrm{t}$, and the constantequivalent consumption $\mathrm{v}_{1}$ for the agent in the next two periods if she manages her first investment well. Then, taking the promised constant-equivalent consumption $\mathrm{v}_{1}$ as given, the old-agent incentive problem determines the investment $\mathrm{h}_{1}$ managed by the agent in period $\mathrm{t}+1$, the consumption $\mathrm{c}_{1}$ for the old agent in period $\mathrm{t}+1$, and the consumption $\mathrm{c}_{2}$ that is promised for the retired agent in period $\mathrm{t}+2$ if she also manages her second investment well.

Let us consider first the old-agent incentive problem: Taking the promise $\mathrm{v}_{1}$ as given, the old-agent incentive problem is to choose $\left(h_{1}, c_{1}, c_{2}\right) \geq 0$ so as to

$$
\text { minimize } c_{1}+\delta c_{2}-h_{1} p_{t+1}
$$




$$
\begin{array}{ll}
\text { subject to }\left(\mathrm{c}_{1}{ }^{\theta}+\delta \mathrm{c}_{2}{ }^{\theta}\right) / \theta=(1+\delta) \mathrm{v}_{1}{ }^{\theta} / \theta & \text { (promise keeping) } \\
\left(\mathrm{c}_{1}{ }^{\theta}+\delta \mathrm{c}_{2}{ }^{\theta}\right) / \theta \geq(1+\delta)\left[\left(\mathrm{c}_{1}+\gamma \mathrm{h}_{1}\right) /(1+\delta)\right]^{\theta} / \theta & \text { (incentive constraint at } t+1) .
\end{array}
$$

The incentive constraint must be binding, or else we could increase $h_{1}$. Now let $\psi=c_{1} / v_{1}$.

Then the equations $\left(\psi \mathrm{v}_{1}\right)^{\theta}+\delta \mathrm{c}_{2}{ }^{\theta}=(1+\delta) \mathrm{v}_{1}{ }^{\theta}$ and $(1+\delta) \mathrm{v}_{1}{ }^{\theta}=\left(\psi \mathrm{v}_{1}+\gamma \mathrm{h}_{1}\right)^{\theta}(1+\delta)^{1-\theta}$ yield

$$
\mathrm{c}_{2}=\mathrm{v}_{1}\left[\left(1+\delta-\psi^{\theta}\right) / \delta\right]^{1 / \theta} \text { and } \mathrm{h}_{1}=\mathrm{v}_{1}(1+\delta-\psi) / \gamma
$$

So the objective is to choose $0 \leq \psi \leq 1$ to

$$
\text { minimize } \mathrm{v}_{1}\left\{\psi+\delta^{1-1 / \theta}\left(1+\delta-\psi^{\theta}\right)^{1 / \theta}-\mathrm{p}_{\mathrm{t}+1}(1+\delta-\psi) / \gamma\right\}
$$

Differentiating with respect to $\psi$, the first-order conditions for an optimum are

$$
1+\mathrm{p}_{\mathrm{t}+1} / \gamma=\delta^{1-1 / \theta}\left(1+\delta-\psi^{\theta}\right)^{1 / \theta-1} \psi^{\theta-1}=\delta^{(\theta-1) / \theta}\left[(1+\delta) / \psi^{\theta}-1\right]^{(1-\theta) / \theta}
$$

This minimum is achieved at

$$
\psi=\left\{(1+\delta) /\left[1+\delta\left(1+\mathrm{p}_{\mathrm{t}+1} / \gamma\right)^{\theta /(1-\theta)}\right]\right\}^{1 / \theta} .
$$

With $\mathrm{p}_{\mathrm{t}+1} \geq 0$ and $\theta \leq 1$, this optimal $\psi$ satisfies $0 \leq \psi \leq 1$. With this optimal $\psi$, the net cost per unit promised $\mathrm{v}_{1}$ in period $\mathrm{t}+1$ is

$$
\mathrm{N}\left(\mathrm{p}_{\mathrm{t}+1}\right)=\psi+\delta^{1-1 / \theta}\left(1+\delta-\psi^{\theta}\right)^{1 / \theta}-\mathrm{p}_{\mathrm{t}+1}(1+\delta-\psi) / \gamma .
$$

In equilibrium, we can only have $\mathrm{p}_{t+1}$ such that this net cost is nonnegative $\mathrm{N}\left(\mathrm{p}_{\mathrm{t}+1}\right) \geq 0$, or else investors would hire old agents to manage investments for just one period.

Next, the young-agent incentive problem is to choose $\left(\mathrm{h}_{0}, \mathrm{c}_{0}, \mathrm{v}_{1}\right) \geq 0$ so as to maximize $\mathrm{p}_{\mathrm{t}} \mathrm{h}_{0}-\mathrm{c}_{0}-\delta \mathrm{N}\left(\mathrm{p}_{\mathrm{t}+1}\right) \mathrm{v}_{1}$ subject to $\mathrm{h}_{0}=1$ and

$$
\left(\mathrm{c}_{0}{ }^{\theta}+\left(\delta+\delta^{2}\right) \mathrm{v}_{1}{ }^{\theta}\right) / \theta \geq\left(1+\delta+\delta^{2}\right)\left[\left(\mathrm{c}_{0}+\gamma \mathrm{h}_{0}\right) /\left(1+\delta+\delta^{2}\right)\right]^{\theta} / \theta \quad \text { (incentive constraint at } t \text { ). }
$$

Let $\mathrm{v}_{0}$ denote the agent's constant-equivalent consumption over her entire life, so that

$$
\left(1+\delta+\delta^{2}\right) \mathrm{v}_{0}{ }^{\theta} / \theta=\left[\mathrm{c}_{0}{ }^{\theta}+\left(\delta+\delta^{2}\right) \mathrm{v}_{1}{ }^{\theta}\right] / \theta .
$$

The incentive constraint at $\mathrm{t}$ must be binding, or else $\mathrm{v}_{1}$ could be reduced, and so

$$
\mathrm{v}_{0}=\left(\mathrm{c}_{0}+\gamma \mathrm{h}_{0}\right) /\left(1+\delta+\delta^{2}\right)>0 .
$$

Let $\zeta$ denote the ratio of the young agent's consumption over her overall constantequivalent consumption, so that $\zeta=\mathrm{c}_{0} / \mathrm{v}_{0}$. Then with the binding incentive constraint, we get

$$
\mathrm{v}_{1}=\mathrm{v}_{0}\left[\left(1+\delta+\delta^{2}-\zeta^{\theta}\right) /\left(\delta+\delta^{2}\right)\right]^{1 / \theta} \text { and } \mathrm{h}_{0}=\mathrm{v}_{0}\left(1+\delta+\delta^{2}-\zeta\right) / \gamma .
$$

For feasibility, we must have $0 \leq \zeta \leq 1+\delta+\delta^{2}$ and also $\zeta \geq\left(1+\delta+\delta^{2}\right)^{1 / \theta}$ if $\theta<0$. Then the expected net profit can be rewritten

$$
\mathrm{v}_{0}\left\{\mathrm{p}_{\mathrm{t}}\left(1+\delta+\delta^{2}-\zeta\right) / \gamma-\zeta-\delta \mathrm{N}\left(\mathrm{p}_{\mathrm{t}+1}\right)\left[\left(1+\delta+\delta^{2}-\zeta^{\theta}\right) /\left(\delta+\delta^{2}\right)\right]^{1 / \theta}\right\}
$$


We are searching for the profit rate $\mathrm{p}_{\mathrm{t}}=\mathrm{Y}\left(\mathrm{p}_{\mathrm{t}+1}\right)$ at which the value of this expected net profit is zero at the optimal solution. We know that $\mathrm{v}_{0}>0$ with any feasible incentive plan that has $\mathrm{h}_{0}=1$. So the expected net profit can be strictly positive if and only if there is some feasible $\zeta$ such that the coefficient of $v_{0}$ in this expected profit formula is positive. That is, at the critical profit rate $\mathrm{p}_{\mathrm{t}}=\mathrm{Y}\left(\mathrm{p}_{\mathrm{t}+1}\right)$ such that investors just expect to break even in hiring a young agent at time $\mathrm{t}$, we must have

$$
0=\operatorname{maximum} \mathrm{p}_{\mathrm{t}}\left(1+\delta+\delta^{2}-\zeta\right) / \gamma-\zeta-\delta \mathrm{N}\left(\mathrm{p}_{\mathrm{t}+1}\right)\left[\left(1+\delta+\delta^{2}-\zeta^{\theta}\right) /\left(\delta+\delta^{2}\right)\right]^{1 / \theta}
$$

where the maximim is over all feasible $\zeta$. (In effect, we have renormalized our problem with the equation $\mathrm{v}_{0}=1$, instead of $\mathrm{h}_{0}=1$.)

It is straightforward to verify that the expected net profit in equation [15] could be made strictly positive with $\zeta=1$ if we had $\mathrm{p}_{\mathrm{t}}>\left(1+\delta \mathrm{N}\left(\mathrm{p}_{\mathrm{t}+1}\right)\right) \gamma /\left(\delta+\delta^{2}\right)$. Thus the profit rate $\mathrm{p}_{\mathrm{t}}=\mathrm{Y}\left(\mathrm{p}_{\mathrm{t}+1}\right)$ that yields a zero maximum in equation [15] must satisfy

$$
0 \leq \mathrm{p}_{\mathrm{t}} \leq\left(1+\delta \mathrm{N}\left(\mathrm{p}_{\mathrm{t}+1}\right)\right) \gamma /\left(\delta+\delta^{2}\right) .
$$

For any $\mathrm{p}_{\mathrm{t}}$, the maximum expected net profit is achieved where $\zeta$ satisfies the first-order conditions

$$
\left(1+\mathrm{p}_{\mathrm{t}} / \gamma\right)\left(\delta+\delta^{2}\right)^{1 / \theta} /\left(\delta \mathrm{N}\left(\mathrm{p}_{\mathrm{t}+1}\right)\right)=\left(1+\delta+\delta^{2}-\zeta^{\theta}\right)^{1 / \theta-1} \zeta^{\theta-1}=\left[\left(1+\delta+\delta^{2}\right) / \zeta^{\theta}-1\right]^{(1-\theta) / \theta},
$$

and so the optimal $\zeta$ is

$$
\zeta=\left(1+\delta+\delta^{2}\right)^{1 / \theta} /\left\{1+\left[\left(\delta+\delta^{2}\right)^{1 / \theta}\left(1+\mathrm{p}_{\mathrm{t}} / \gamma\right) /\left(\delta \mathrm{N}\left(\mathrm{p}_{\mathrm{t}+1}\right)\right)\right]^{\theta /(1-\theta)}\right\}^{1 / \theta} .
$$

Thus, to find $\mathrm{p}_{\mathrm{t}}=\mathrm{Y}\left(\mathrm{p}_{\mathrm{t}+1}\right)$, we can search over the interval from 0 to $\left(1+\delta \mathrm{N}\left(\mathrm{p}_{\mathrm{t}+1}\right)\right) \gamma /\left(\delta+\delta^{2}\right)$ to find where this optimal $\zeta$ yields the zero expected net profit in equation [15].

The full optimal solution to the original incentive problem with $h_{0}=1$ and $p_{t}=Y\left(p_{t+1}\right)$ can then be computed from the optimal $\zeta$ by the equations

$$
\begin{aligned}
& \mathrm{v}_{0}=\gamma \mathrm{h}_{0} /\left(1+\delta+\delta^{2}-\zeta\right), \\
& \mathrm{v}_{1}=\mathrm{v}_{0}\left[\left(1+\delta+\delta^{2}-\zeta^{\theta}\right) /\left(\delta+\delta^{2}\right)\right]^{1 / \theta}, \\
& \mathrm{c}_{1}=\mathrm{v}_{1}\left\{(1+\delta) /\left[1+\delta\left(1+\mathrm{p}_{\mathrm{t}+1} / \gamma\right)^{\theta /(1-\theta)}\right]\right\}^{1 / \theta}, \\
& \mathrm{h}_{1}=\left[\mathrm{v}_{1}(1+\delta)-\mathrm{c}_{1}\right] / \gamma, \\
& \mathrm{c}_{2}=\left\{\left[(1+\delta) \mathrm{v}_{1}{ }^{\theta}-\mathrm{c}_{1}{ }^{\theta}\right] / \delta\right\}^{1 / \theta} .
\end{aligned}
$$

\section{Appendix B. Construction of unstable dynamic equilibria in the regular case}

Fact 2. Suppose that $1<\mathrm{G}\left(\mathrm{p}^{*}\right)<1 / \delta$ and a cycle $\left(\mathrm{q}_{0}, \mathrm{q}_{1}\right)$ exists as in the regular case 
from Fact 1. For any initial condition $\mathrm{V}_{0}$ other than $\mathrm{V}^{*}$, there exists an equilibrium that begins with this initial condition and, within finitely many periods, enters the extreme $\left(\mathrm{q}_{0}, \mathrm{q}_{1}\right)$ cycle.

Proof. First let us check the easy case when $\mathrm{V}_{0} \geq \mathrm{I}\left(\mathrm{Y}\left(\mathrm{q}_{0}\right)\right) / \mathrm{H}\left(\mathrm{Y}\left(\mathrm{q}_{0}\right)\right)$. In this case we get an equilibrium that begins with $\mathrm{J}_{1}=0$ and with the $\mathrm{p}_{1} \leq \mathrm{Y}\left(\mathrm{q}_{0}\right)$ that satisfies $\mathrm{I}\left(\mathrm{p}_{1}\right) / \mathrm{H}\left(\mathrm{p}_{1}\right)=\mathrm{V}_{0}$ (notice that $\mathrm{I}\left(\mathrm{p}_{1}\right) / \mathrm{H}\left(\mathrm{p}_{1}\right)$ is a decreasing function of $\mathrm{p}_{1}$ and is unbounded as $\mathrm{p}_{1}$ approaches 0 with $\mathrm{H}(0)=0)$, and thereafter continues in the extreme $\left(\mathrm{q}_{0}, \mathrm{q}_{1}\right)$ cycle beginning with $\mathrm{p}_{2}=\mathrm{q}_{0}$.

So it remains for us to show how to find equilibria in which the initial promise to old agents at period 1 is any $\mathrm{V}_{0}$ such that

$$
0 \leq \mathrm{V}_{0}<\mathrm{I}\left(\mathrm{Y}\left(\mathrm{q}_{0}\right)\right) / \mathrm{H}\left(\mathrm{Y}\left(\mathrm{q}_{0}\right)\right) \text {. }
$$

Let $\mathrm{T}$ denote the first period when no new agents are hired, and so $\mathrm{J}_{\mathrm{T}}=0$. After period $\mathrm{T}$, the equilibrium will follow the $\left(\mathrm{q}_{0}, \mathrm{q}_{1}\right)$ cycle, with $\mathrm{p}_{\mathrm{T}+\mathrm{t}}=\mathrm{q}_{0}, \mathrm{~J}_{\mathrm{T}+\mathrm{t}}=\mathrm{I}\left(\mathrm{q}_{0}\right), \mathrm{p}_{\mathrm{T}+\mathrm{t}+1}=\mathrm{q}_{1}$, and $\mathrm{J}_{\mathrm{T}+\mathrm{t}+1}=0$ for every odd positive $t$. Now consider any $\mathrm{p}_{\mathrm{T}}$ such that

$$
\mathrm{q}_{1} \leq \mathrm{p}_{\mathrm{T}} \leq \mathrm{Y}\left(\mathrm{q}_{0}\right)=\mathrm{Y}\left(\mathrm{Y}\left(\mathrm{q}_{1}\right)\right) .
$$

The condition $\mathrm{p}_{\mathrm{T}} \leq \mathrm{Y}\left(\mathrm{q}_{0}\right)$ implies that the equilibrium can continue in the $\left(\mathrm{q}_{0}, \mathrm{q}_{1}\right)$ cycle after period $\mathrm{T}$, starting with $\mathrm{J}_{\mathrm{T}}=0$ and $\mathrm{p}_{\mathrm{T}+1}=\mathrm{q}_{0}$. With $\mathrm{J}_{\mathrm{T}}=0$, we can recursively compute the equilibrium backwards in time from $\mathrm{T}$ by the formulas

$$
\mathrm{p}_{\mathrm{T}-\mathrm{t}-1}=\mathrm{Y}\left(\mathrm{p}_{\mathrm{T}-\mathrm{t}}\right) \text { and } \mathrm{J}_{\mathrm{T}-\mathrm{t}-1}=\left[\mathrm{I}\left(\mathrm{p}_{\mathrm{T}-\mathrm{t}}\right)-\mathrm{J}_{\mathrm{T}-\mathrm{t}}\right] / \mathrm{G}\left(\mathrm{p}_{\mathrm{T}-\mathrm{t}}\right) \text {. }
$$

We now show that these $\mathrm{p}_{\mathrm{T}-\mathrm{t}}$ and $\mathrm{J}_{\mathrm{T}-\mathrm{t}}$ values will be nonnegative, so that this sequence $\left(\mathrm{p}_{\mathrm{T}-\mathrm{t}}, \mathrm{J}_{\mathrm{T}-\mathrm{t}}\right)$ can satisfy our equilibrium conditions for all $\mathrm{t}$. With $\mathrm{Y}$ decreasing, from the initial $\mathrm{p}_{\mathrm{T}}$ between $\mathrm{q}_{1}$ and $\mathrm{Y}^{2}\left(\mathrm{q}_{1}\right)$, the $\mathrm{p}$ sequence must inductively satisfy, for each nonnegative integer $\mathrm{s}$,

$$
\mathrm{Y}^{2 \mathrm{~s}}\left(\mathrm{q}_{1}\right) \leq \mathrm{p}_{\mathrm{T}-2 \mathrm{~s}} \leq \mathrm{Y}^{2 \mathrm{~s}+2}\left(\mathrm{q}_{1}\right) \leq \mathrm{p}^{*} \leq \mathrm{Y}^{2 \mathrm{~s}+3}\left(\mathrm{q}_{1}\right) \leq \mathrm{p}_{\mathrm{T}-2 \mathrm{~s}-1} \leq \mathrm{Y}^{2 \mathrm{~s}+1}\left(\mathrm{q}_{1}\right) .
$$

With regularity, $\mathrm{Y}^{2 \mathrm{~s}}\left(\mathrm{q}_{1}\right)$ is an increasing sequence and $\mathrm{Y}^{2 \mathrm{~s}+1}\left(\mathrm{q}_{1}\right)$ is a decreasing sequence, both converging to $\mathrm{p}^{*}$ as $\mathrm{s} \rightarrow+\infty$. So the $\mathrm{p}_{\mathrm{T}-\mathrm{t}}$ are bounded away from 0 , and $\mathrm{p}_{\mathrm{T}-\mathrm{t}} \rightarrow \mathrm{p}^{*}$ as $\mathrm{t} \rightarrow \infty$. With $\mathrm{J}_{\mathrm{T}}=0$, we get $\mathrm{J}_{\mathrm{T}-1}=\mathrm{I}\left(\mathrm{p}_{\mathrm{T}}\right) / \mathrm{G}\left(\mathrm{p}_{\mathrm{T}}\right) \geq 0$. Then, for any integer $\mathrm{t} \geq 0$ we get

$$
\mathrm{J}_{\mathrm{T}-\mathrm{t}-2}=\left[\mathrm{I}\left(\mathrm{Y}\left(\mathrm{p}_{\mathrm{T}-\mathrm{t}}\right)\right) \mathrm{G}\left(\mathrm{p}_{\mathrm{T}-\mathrm{t}}\right)-\mathrm{I}\left(\mathrm{p}_{\mathrm{T}-\mathrm{t}}\right)+\mathrm{J}_{\mathrm{T}-\mathrm{t}} \mathrm{t} /\left[\mathrm{G}\left(\mathrm{p}_{\mathrm{T}-\mathrm{t}}\right) \mathrm{G}\left(\mathrm{p}_{\mathrm{T}-\mathrm{t}-1}\right)\right] \geq 0,\right.
$$

because $\mathrm{p}_{\mathrm{T}-\mathrm{t}} \geq \mathrm{q}_{1}$ and so $\mathrm{I}\left(\mathrm{Y}\left(\mathrm{p}_{\mathrm{T}-\mathrm{t}}\right)\right) \mathrm{G}\left(\mathrm{p}_{\mathrm{T}-\mathrm{t}}\right) \geq \mathrm{I}\left(\mathrm{p}_{\mathrm{T}-\mathrm{t}}\right)$. So the $\mathrm{J}_{\mathrm{T}-\mathrm{t}}$ are all nonnegative. Thus, our $\left(\mathrm{p}_{\mathrm{T}-\mathrm{t}}, \mathrm{J}_{\mathrm{T}-\mathrm{t}}\right)$ values satisfy the conditions for an equilibrium before the $\left(\mathrm{q}_{0}, \mathrm{q}_{1}\right)$ cycle starts at $\mathrm{T}+1$.

With $\mathrm{p}_{\mathrm{T}-\mathrm{t}} \rightarrow \mathrm{p}^{*}$, the recursive formula for $\mathrm{J}_{\mathrm{T}-\mathrm{t}-1}$ implies that $\left(\mathrm{J}_{\mathrm{T}-\mathrm{t}-1}-\mathrm{J}^{*}\right) /\left(\mathrm{J}_{\mathrm{T}-\mathrm{t}} \mathrm{J}^{*}\right)$ must converge to $-1 / \mathrm{G}\left(\mathrm{p}^{*}\right)$. So with $\mathrm{G}\left(\mathrm{p}^{*}\right)>1$, the $\mathrm{J}_{\mathrm{T}-\mathrm{t}}$ sequence must converge to $\mathrm{J}^{*}$ as $\mathrm{t} \rightarrow+\infty$. 
Among the possible $\mathrm{p}_{\mathrm{T}}$ between $\mathrm{q}_{1}$ and $\mathrm{Y}^{2}\left(\mathrm{q}_{1}\right)$, the extreme case of $\mathrm{p}_{\mathrm{T}}=\mathrm{q}_{1}$ yields $\mathrm{p}_{\mathrm{T}-2}=\mathrm{Y}^{2}\left(\mathrm{q}_{1}\right)$ and $\mathrm{J}_{\mathrm{T}-2}=\left[\mathrm{I}\left(\mathrm{Y}\left(\mathrm{q}_{1}\right)\right)-\mathrm{I}\left(\mathrm{q}_{1}\right) / \mathrm{G}\left(\mathrm{q}_{1}\right)\right] / \mathrm{G}\left(\mathrm{Y}\left(\mathrm{q}_{1}\right)\right)=0$, which is the same as the $\left(\mathrm{p}_{\mathrm{T}}, \mathrm{J}_{\mathrm{T}}\right)$ for the opposite extreme case of $\mathrm{p}_{\mathrm{T}}=\mathrm{Y}^{2}\left(\mathrm{q}_{1}\right)$. So the equilibrium for $\mathrm{p}_{\mathrm{T}}=\mathrm{q}_{1}$ is the same as the equilibrium for $\mathrm{p}_{\mathrm{T}}=\mathrm{Y}^{2}\left(\mathrm{q}_{1}\right)$ two periods later. Thus, as we trace out the different equilibrium paths for $\mathrm{p}_{\mathrm{T}}$ between $\mathrm{q}_{1}$ and $\mathrm{Y}^{2}\left(\mathrm{q}_{1}\right)$, each $\left(\mathrm{p}_{\mathrm{T}-\mathrm{t}}, \mathrm{J}_{\mathrm{T}-\mathrm{t}}\right)$ pair traces out a continuous curve that connects at the $\mathrm{Y}^{2}\left(\mathrm{q}_{1}\right)$ end with the $\left(\mathrm{p}_{\mathrm{T}-\mathrm{t}-2}, \mathrm{~J}_{\mathrm{T}-\mathrm{t}-2}\right)$ curve at its $\mathrm{q}_{1}$ end. As we vary $\mathrm{t}$ over all nonnegative integers, the curves from the odd $t$ and the even $t$ must connect in the limit at $\left(\mathrm{p}^{*}, \mathrm{~J}^{*}\right)$.

For any $\mathrm{t} \geq 0$, the total promises $\mathrm{V}_{\mathrm{T}-\mathrm{t}-1}$ to old agents that would justify starting this equilibrium path at period $\mathrm{T}-\mathrm{t}$ are

$$
\mathrm{V}_{\mathrm{T}-\mathrm{t}-1}=\mathrm{J}_{\mathrm{T}-\mathrm{t}-1} \mathrm{G}\left(\mathrm{p}_{\mathrm{T}-\mathrm{t}}\right) / \mathrm{H}\left(\mathrm{p}_{\mathrm{T}-\mathrm{t}}\right)=\left[\mathrm{I}\left(\mathrm{p}_{\mathrm{T}-\mathrm{t}}\right)-\mathrm{J}_{\mathrm{T}-\mathrm{t}}\right] / \mathrm{H}\left(\mathrm{p}_{\mathrm{T}-\mathrm{t}}\right) \text {. }
$$

We get $\mathrm{V}_{\mathrm{T}-1}=\mathrm{I}\left(\mathrm{Y}\left(\mathrm{q}_{0}\right)\right) / \mathrm{H}\left(\mathrm{Y}\left(\mathrm{q}_{0}\right)\right)$ in the case of $\mathrm{p}_{\mathrm{T}}=\mathrm{Y}\left(\mathrm{q}_{0}\right)=\mathrm{Y}^{2}\left(\mathrm{q}_{1}\right)$. We get $\mathrm{V}_{\mathrm{T}-2}=0$ in the case of $\mathrm{p}_{\mathrm{T}}=\mathrm{q}_{1}$. So as we vary $\mathrm{p}_{\mathrm{T}}$ between $\mathrm{q}_{1}$ and $\mathrm{Y}\left(\mathrm{q}_{0}\right)$ and vary $\mathrm{t}$ over all positive integers, these $\mathrm{V}_{\mathrm{T}-\mathrm{t}-1}$ values cover the interval from 0 to $\mathrm{I}\left(\mathrm{Y}\left(\mathrm{q}_{0}\right)\right) / \mathrm{H}\left(\mathrm{Y}\left(\mathrm{q}_{0}\right)\right)$. Thus, we can find some $\mathrm{p}_{\mathrm{T}}$ and $\hat{t}$ that matches $\mathrm{V}_{\mathrm{T}-\hat{\mathrm{t}}-1}$ to any given $\mathrm{V}_{0}$ in this interval, and then we can let $\mathrm{T}=\hat{\mathrm{t}}+1$ and apply the computed equilibrium. $Q E D$.

As an example of the algorithm described in the above proof, Figures 2, 3, and 4 show a dynamic equilibrium that enters the extreme $\left(\mathrm{q}_{0}, \mathrm{q}_{1}\right)$ cycle after period $\mathrm{T}=25$, where the equilibrium profit rate $\mathrm{p}_{\mathrm{T}}=0.153$ is halfway between $\mathrm{q}_{1}=0.141$ and $\mathrm{Y}\left(\mathrm{q}_{0}\right)=0.165$.

In the case when $\mathrm{G}\left(\mathrm{p}^{*}\right)>1 / \delta$, dynamic equilibria that converge to the steady state can be computed from a selected initial profit rate $\mathrm{p}_{1}$ by recursively solving the equations $\mathrm{p}_{\mathrm{t}}=\mathrm{Y}\left(\mathrm{p}_{\mathrm{t}+1}\right)$ for $\mathrm{p}_{\mathrm{t}+1}$ forward from $\mathrm{t}=1$. Then, picking a distant future period $\mathrm{T}$ after profit rates have converged very close to the steady state $\mathrm{p}^{*}$, we can estimate that the young-agent investments $\mathbf{J}_{\mathrm{T}}$ there should be close to the steady state $\mathrm{J}^{*}$, and then we can compute earlier $\mathrm{J}_{\mathrm{t}}$ from $\mathrm{J}_{\mathrm{T}} \approx \mathrm{J} *$ by recursively applying $\mathrm{J}_{\mathrm{t}-1}=\left(\mathrm{I}\left(\mathrm{p}_{\mathrm{t}}\right)-\mathrm{J}_{\mathrm{t}}\right) / \mathrm{G}\left(\mathrm{p}_{\mathrm{t}}\right)$ backward in time from $\mathrm{t}=\mathrm{T}$. 


\section{References}

Gary Becker and George Stigler, "Law enforcement, malfeasance, and compensation of enforcers," Journal of Legal Studies 3(1):1-18 (1974).

Ben Bernanke and Mark Gertler, "Agency costs, net worth, and business fluctuations," American Economic Review 79(1):14-31 (1989).

Roger B. Myerson, "A model of moral-hazard credit cycles" Journal of Political Economy 120(5):847-878 (2012).

Carl Shapiro and Joseph E. Stiglitz, "Equilibrium unemployment as a worker disciplinary device," American Economic Review 74(3):433-444 (1984). 


\begin{tabular}{|c|c|c|c|c|c|c|c|}
\hline$\theta$ & $\mathrm{p}^{*}$ & $\mathrm{Y}\left(\mathrm{p}^{*}\right)$ & $\mathrm{h}_{\mathbf{0}}$ & $\mathrm{c}_{0}$ & $\mathrm{~h}_{1}$ & $\mathrm{c}_{1}$ & $\mathrm{c}_{2}$ \\
\hline 1 & 0.125 & -1 & 1 & 0 & 2 & 0 & 1 \\
\hline 0.9 & 0.147 & -1.075 & 1 & 0.000 & 2.151 & 0.012 & 1.200 \\
\hline 0.8 & 0.172 & -1.041 & 1 & 0.002 & 2.083 & 0.089 & 1.218 \\
\hline 0.7 & 0.194 & -0.978 & 1 & 0.009 & 1.955 & 0.170 & 1.157 \\
\hline 0.6 & 0.214 & -0.917 & 1 & 0.022 & 1.834 & 0.232 & 1.087 \\
\hline 0.5 & 0.231 & -0.864 & 1 & 0.038 & 1.727 & 0.275 & 1.021 \\
\hline 0.3 & 0.260 & -0.777 & 1 & 0.070 & 1.554 & 0.329 & 0.909 \\
\hline 0.1 & 0.282 & -0.712 & 1 & 0.098 & 1.424 & 0.356 & 0.824 \\
\hline-0.1 & 0.299 & -0.662 & 1 & 0.123 & 1.324 & 0.371 & 0.758 \\
\hline-0.5 & 0.325 & -0.591 & 1 & 0.160 & 1.183 & 0.381 & 0.664 \\
\hline-1 & 0.346 & -0.535 & 1 & 0.193 & 1.071 & 0.383 & 0.591 \\
\hline-2 & 0.372 & -0.473 & 1 & 0.232 & 0.946 & 0.376 & 0.510 \\
\hline-4 & 0.395 & -0.419 & 1 & 0.269 & 0.838 & 0.364 & 0.441 \\
\hline
\end{tabular}

Table 1. Dependence of steady-state contracts on utility exponent $\theta$, with $\delta=0.5$ and $\gamma=0.25$. 


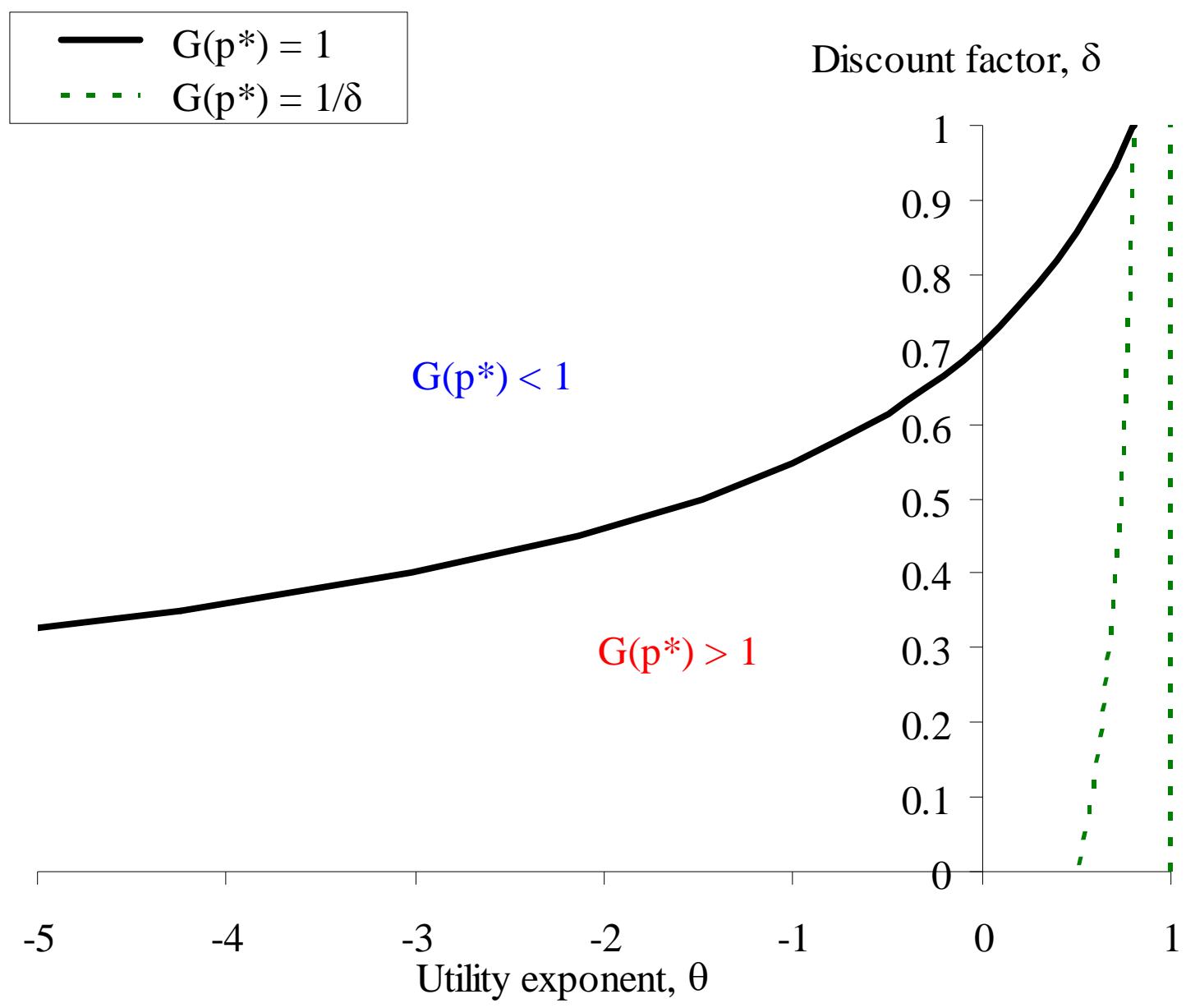

Figure 1. Conditions for existence of cycles around the steady state $\left(\mathrm{G}\left(\mathrm{p}^{*}\right)>1\right)$ depend on the discount factor $\delta$ and the utility exponent $\theta$. 


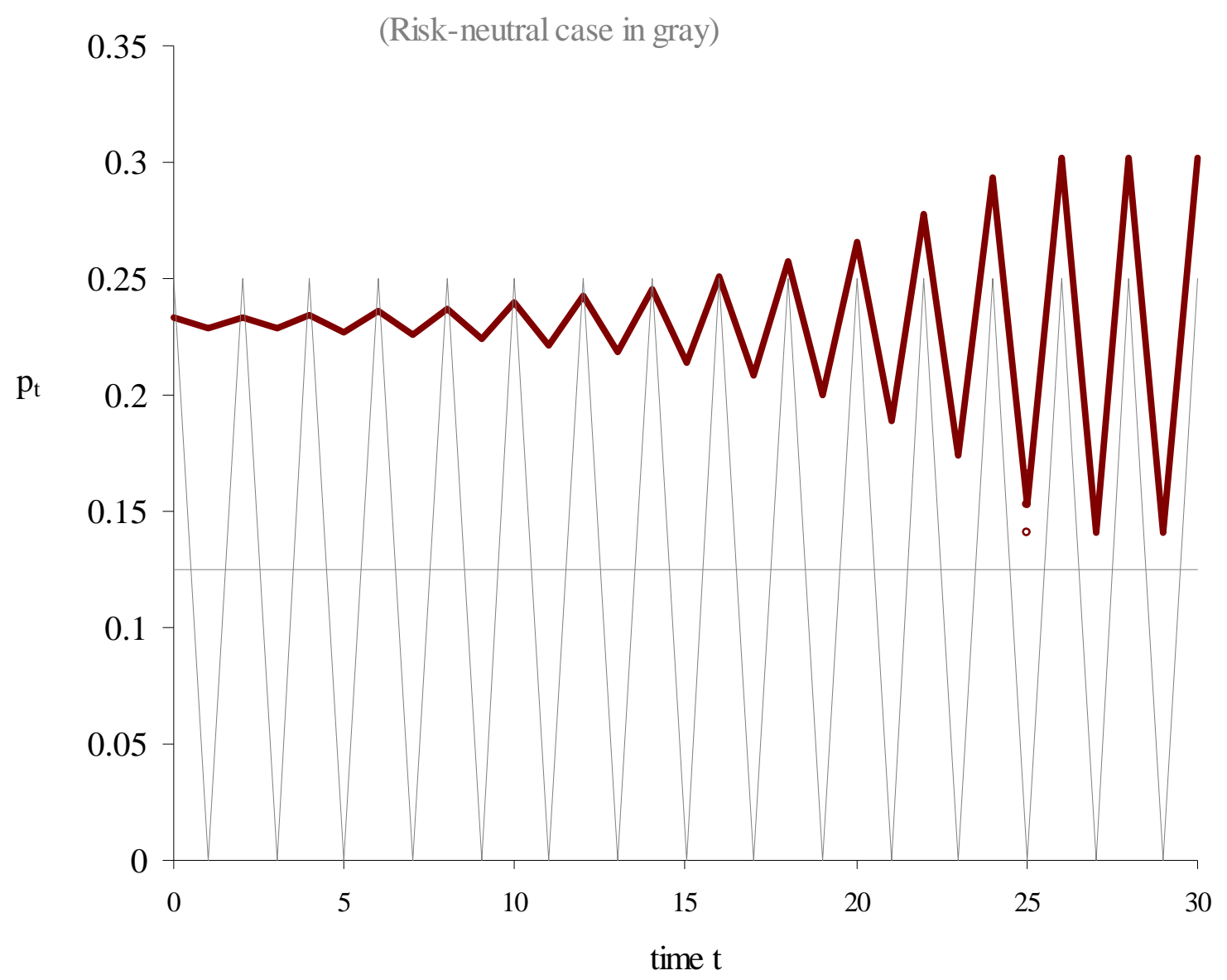

Figure 2. Profit rates in a dynamic equilibrium with parameters $\theta=0.5, \delta=0.5, \gamma=0.25$, $\mathrm{I}(\mathrm{p})=1.5 \max \{1-\mathrm{p} / 0.7,0\}$, and with the initial $\mathrm{V}_{0} 3 \%$ from steady state $\mathrm{V}^{*}$. (The widest cycle and steady state with risk-neutral agents are shown in gray, for comparison.) 


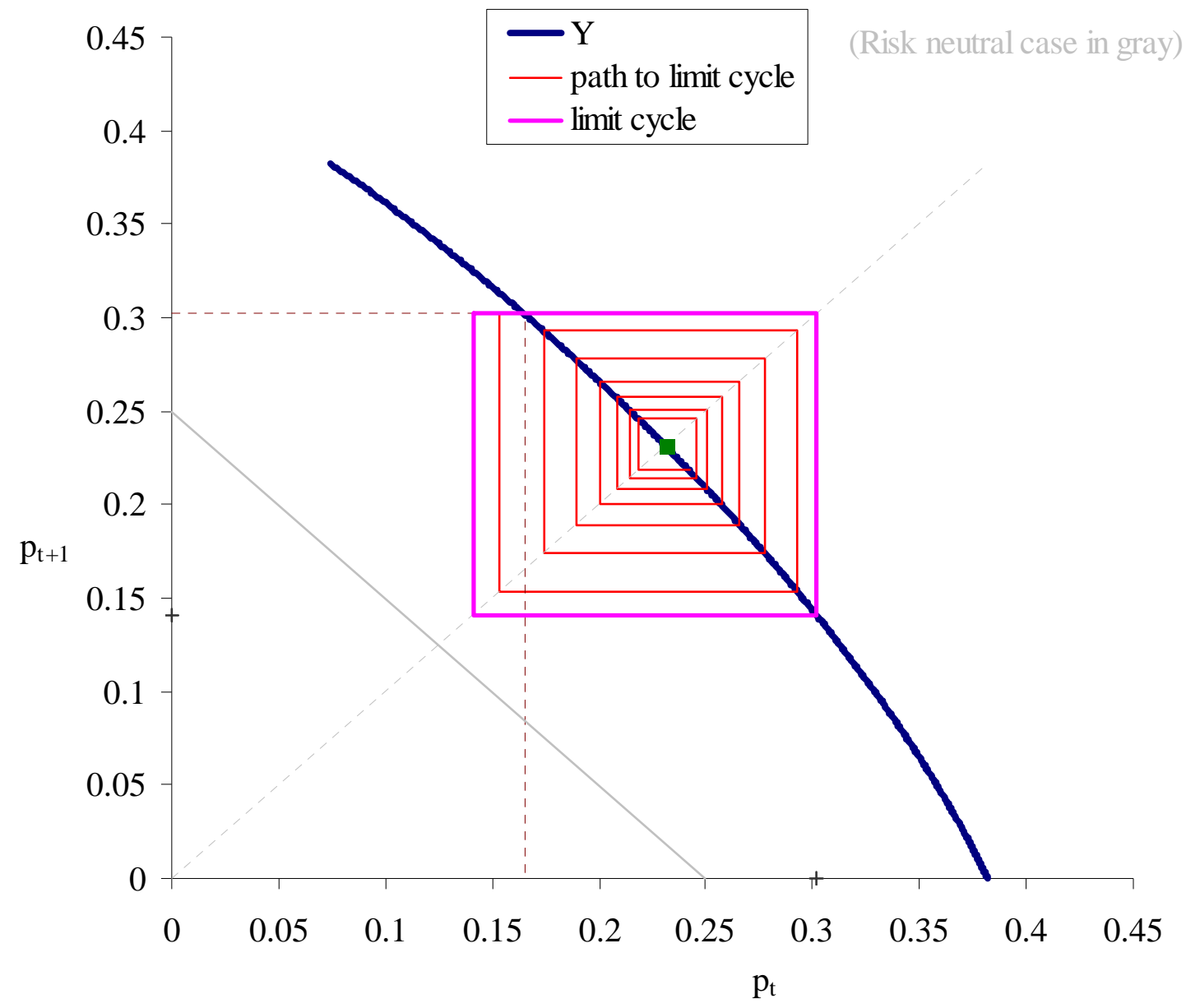

Figure 3. Divergence of profit rates $\mathrm{p}_{\mathrm{t}}=\mathrm{Y}\left(\mathrm{p}_{\mathrm{t}+1}\right)$ in a cob-web diagram.

(Parameters: $\theta=0.5, \delta=0.5, \gamma=0.25, \mathrm{I}(\mathrm{p})=1.5 \max \{1-\mathrm{p} / 0.7,0\}$.) 


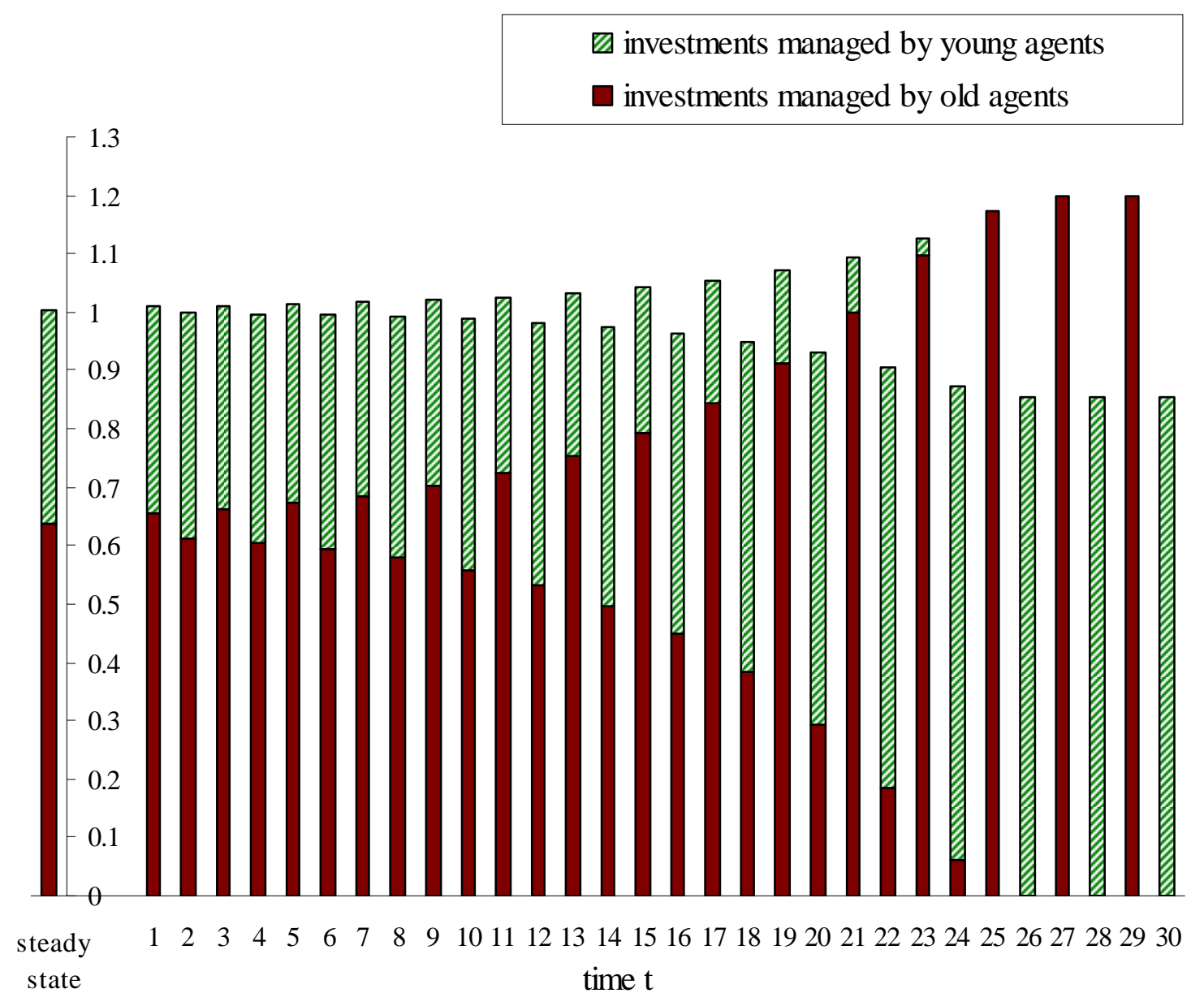

Figure 4. Development of generational inequalities between investments managed by young agents $J_{t}$ and old agents $I\left(p_{t}\right)-J_{t}$ over time. (Same parameters as Figure 2.) 


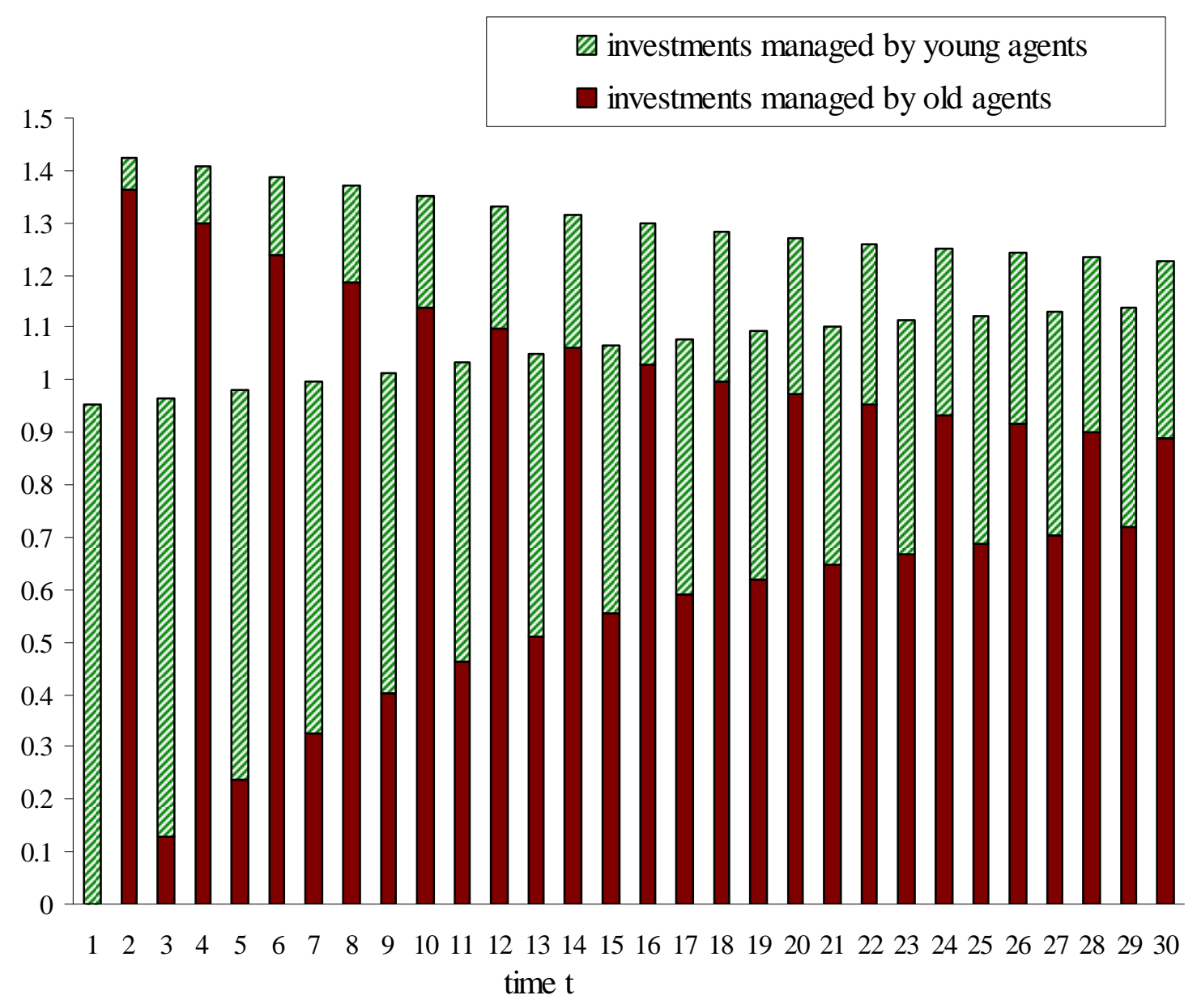

Figure 5. Investments managed by young agents $J_{t}$ and old agents $I\left(p_{t}\right)-J_{t}$ in a dynamic equilibrium with $\mathrm{V}_{0}=0, \theta=0.9, \delta=0.5, \gamma=0.25, \mathrm{I}(\mathrm{p})=1.5 \max \{1-\mathrm{p} / 0.7,0\}$. 


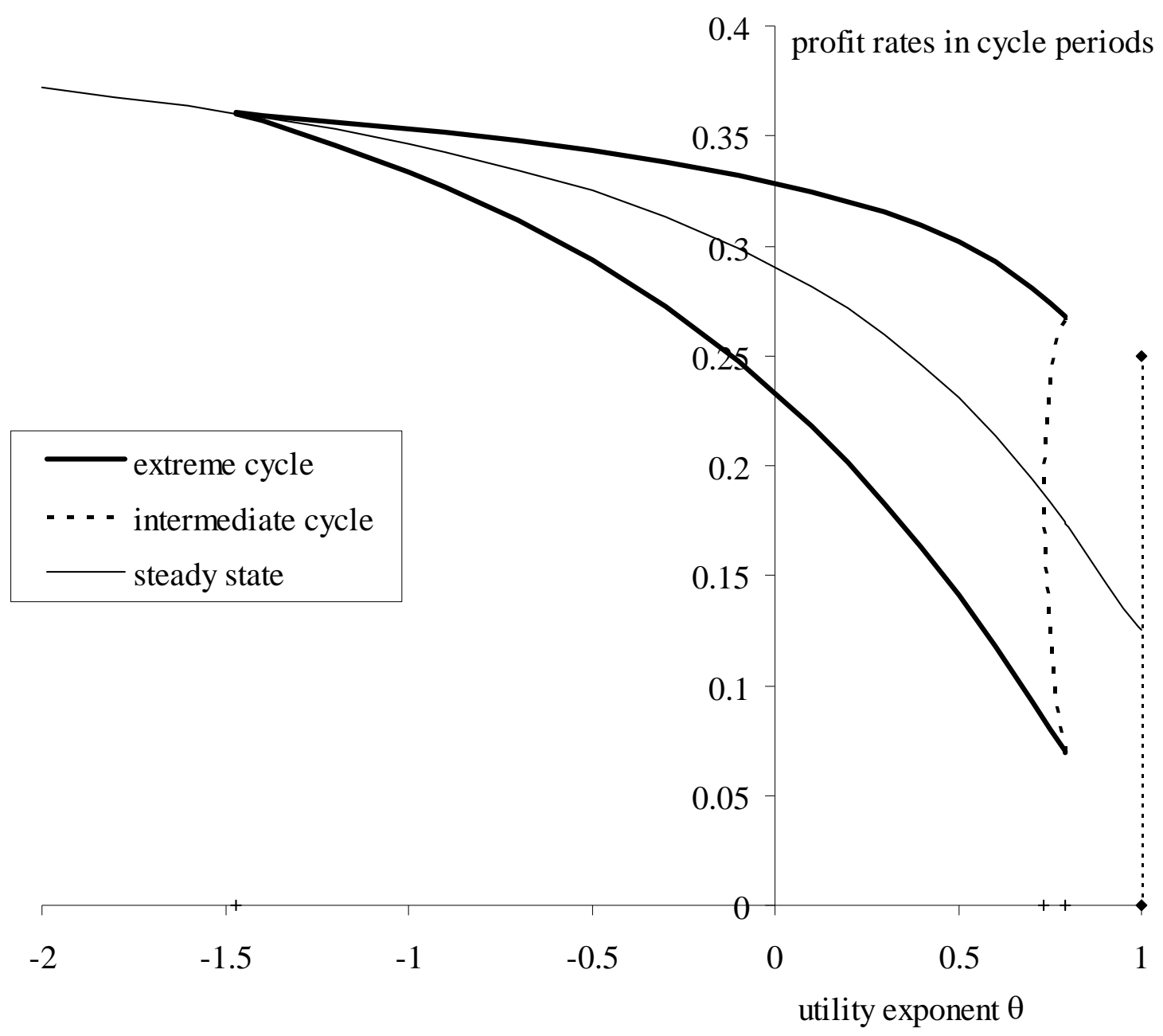

Figure 6. Bifurcation diagram showing profit rates in cyclical periods for the extreme cycle (with $-1.47 \leq \theta \leq 0.793$ ), an unstable intermediate cycle (with $0.735 \leq \theta \leq 0.793$ ), and the steady state (all $\theta$ ) with parameters $\delta=0.5, \gamma=0.25, \mathrm{I}(\mathrm{p})=1.5 \max \{1-\mathrm{p} / 0.7,0\}$. 


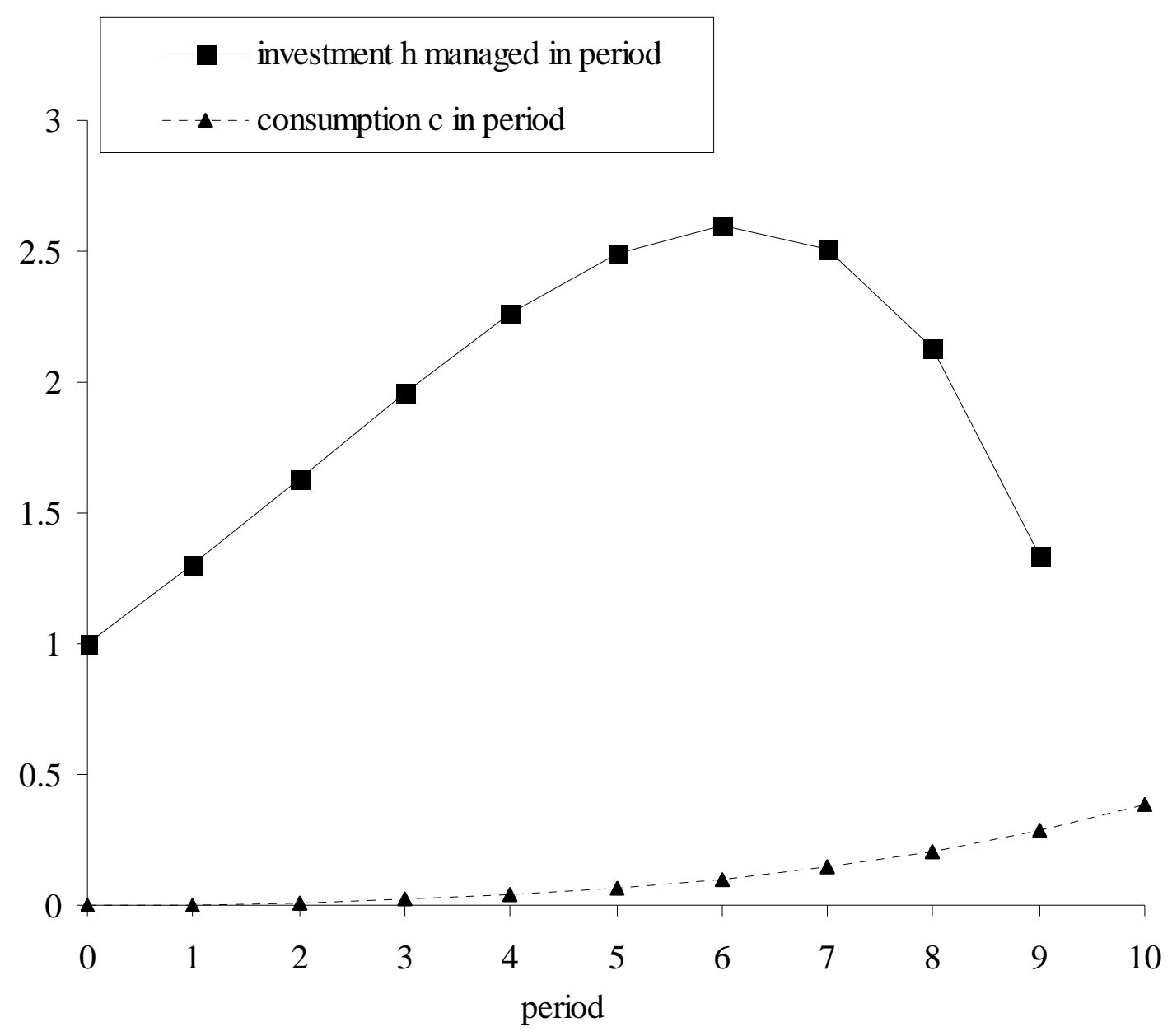

Figure 7. Relative size of investment responsibilities and consumption for agents over a career of $n=10$ periods, in steady state with $\theta=0.5, \delta=0.25^{0.1}=0.871, \gamma=0.25$, and $\mathrm{p}^{*}=0.0409$. 


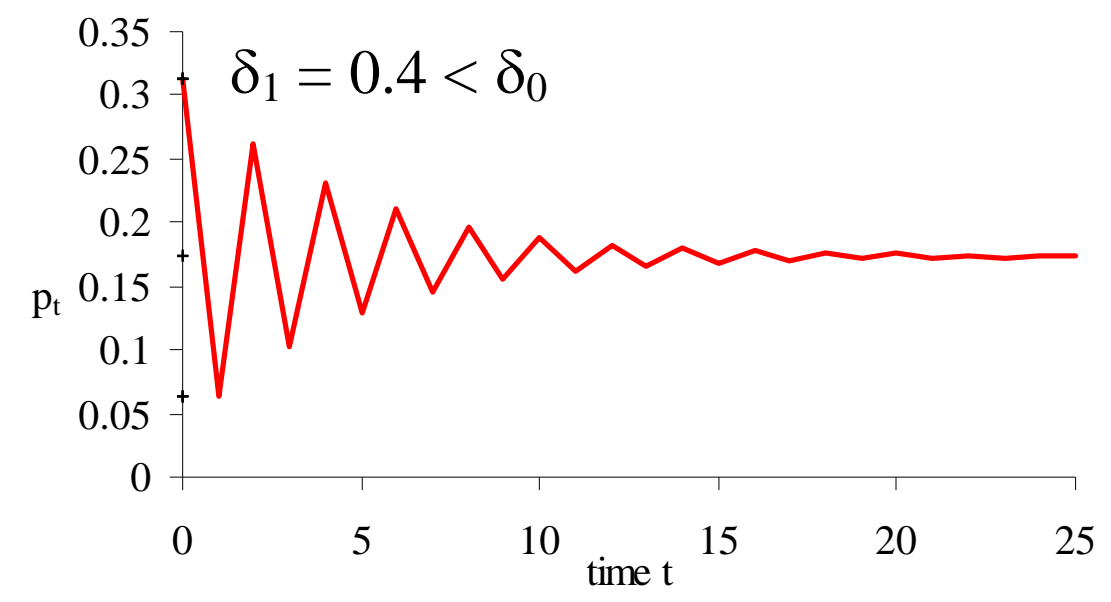

Figure 8. Profit rates in a dynamic equilibrium with risk-neutral agents having discount factor $\delta_{1}=0.4$, while investors' discount factor is $\delta_{0}=0.5$, with $\gamma=0.25, \mathrm{I}(\mathrm{p})=1.5 \max \{1-\mathrm{p} / 0.7,0\}$.

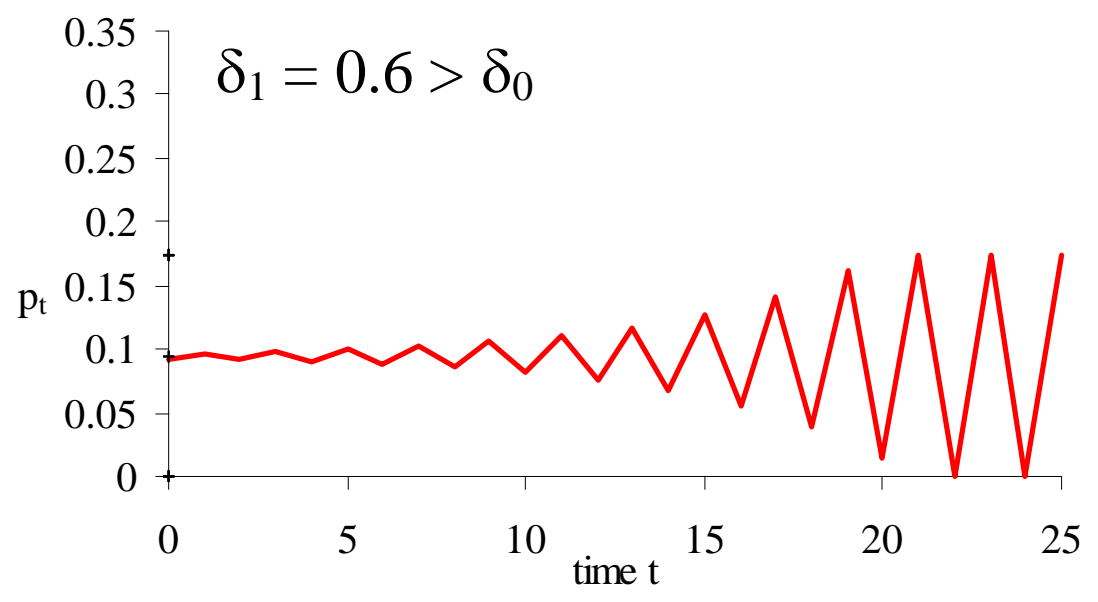

Figure 9. Profit rates in a dynamic equilibrium with risk-neutral agents having discount factor $\delta_{1}=0.6$, while investors' discount factor is $\delta_{0}=0.5$, with $\gamma=0.25, \mathrm{I}(\mathrm{p})=1.5 \max \{1-\mathrm{p} / 0.7,0\}$. 